\title{
A Comprehensive Study on Re-arrangement of Modules Based TCT Configurations of Partial Shaded PV Array with Shade Dispersion Method
}

\author{
V. Bala Raju, Dr. Ch. Chengaiah \\ Dept. of EEE, SVU College of Engg., SV University, Tirupati, India
}

Received December 23, 2019; Accepted January 29, 2020; Published February 12, 2020

\begin{abstract}
The conventional Total-Cross-Tied (TCT) Solar photovoltaic (SPV) array configuration has the highest power output as compared to other configurations or topologies in most cases of partial shading. But the performance of TCT configuration is affected under shading conditions, resulting in multiple peaks occurring in the output PV characteristics. To improve the performance of TCT array configuration under different shading scenarios, it is only necessary to reposition or rearrange the PV modules in the TCT Solar PV array based on the arrangement of puzzle numbers, without altering the electrical contacts of the TCT array configuration. The main objective of this study is to investigate the performance of rearrangement of modules in SPV array based new TCT array configurations with shade dispersion technique and compare the global maximum peak power (GMPP) of SPV array, mismatch losses, Fill-Factor, efficiency and number of required electrical connections or ties between array modules with proposed optimal arrangement of modules under shading (non-uniform irradiance) conditions. For this study, one uniform irradiance case and total 14 partial shading patterns were considered. MATLAB/Simulink software was used for modeling and simulation of $6 \times 6$ size different rearrangement based TCT array and proposed optimal SPV array configurations.
\end{abstract}

Keywords: Photovoltaic cells and modules; Array output power; Interconnections; Mismatch power losses; Fill-factor; Efficiency; Partial shading

\section{Introduction}

The freely available irradiance in the atmosphere is directly converted into electricity through the photovoltaic (PV) effect with the help of solar photovoltaic (SPV) cells in a PV module. The freely available solar energy is used for different applications in our daily life. The first solar photovoltaic cell was developed in 1954 with a very low efficiency of $5 \%$ which has now reached up to $25 \%$. The efficiency of PV modules gradually reduced to a lower value of less than $10 \%$, because of partial shading effect in an array [1-4]. The performance of a SPV array under shading conditions can be improved by means of reconfiguration methods. The main conventional PV array configurations are parallel, series, series-parallel(S-P), Honeycomb (HC), bridge linked (BL) and total cross-tied (TCT) type [5-6] of connections. Among all conventional type, the TCT has the highest power output and minimum mismatch losses under various shading scenarios as presented in the literature [6-8]. The main I-V characteristic 
parameters are $V_{o c}, V_{m}, I_{s c}, I_{m}$ and $P_{m}$. The factors including manufacturer tolerance, uneven surface soiling, light-induced power degradation, discoloration and cracking are responsible for the I-V mismatch (differences of I-V parameters of $\mathrm{PV}$ modules in the SPV array) in modules, which causes mismatch losses in the SPV array and typically $4 \%$ to $7 \%$ energy loss. The performance of the TCT configuration is improved under shading conditions by repositioning or rearrangement of the modules based on puzzle patterns in an array configuration. In the TCT configuration based on number puzzles, the arrangement of modules mainly includes Sudoku, Arrow Sudoku, Ken-Ken, Skyscrapers, Non-symmetric, Chaotic-Based-Map, Odd-Even, Futoshiki, Latin square, Magic square, current based arrangement $\left(\mathrm{I}_{\mathrm{m}}\right.$ based TCT) and voltage based arrangement $\left(\mathrm{V}_{\mathrm{m}}\right.$ based TCT) photovoltaic configurations [8-10]. Based on the shading pattern, the optimal location of each module in the TCT SPV array is determined with the help of puzzle number analysis without modifying the electrical interconnections among the modules. In this article, the various rearrangement methods used for enhancing the maximum power of the SPV array under shaded conditions presented in the literature are analyzed, and the parameters such as global maximum power (PGMPP), mismatch losses (mmlosses), fillfactor $(\mathrm{FF})$ and efficiency are compared. This paper proposes an optimal interconnection for a $6 \times 6$ size TCT array configuration under 14 different possible shading scenarios. Compared to S-P and rearrangement-based TCT SPV array connections, the proposed optimal interconnection technique minimizes the requirement of number of electrical interconnections or ties among modules and also reduces mismatched power losses. The optimal method proposed creates an alternative path for current distribution between modules under unshaded and partially shaded conditions with minimum number of interconnections or ties. The performance of the TCT array topology is improved by rearrangement of modules to the optimal location, but wiring losses increase due to repositioning of every module in an entire array configuration. The proposed method minimizes the installation cost, requirement of wires, wiring installation time and complexity of interconnections among modules as compared to rearrangement modules based TCT configurations of the SPV system. The output array power of the optimal method is nearly same as rearranged based TCT configuration by considering wiring losses of repositioning modules in an array.

\section{System Design}

\subsection{Mathematical Modelling of Solar PV Cell and Array}

The solar PV cell converts solar PV energy into electrical energy. Figure 1 shows the equivalent circuit of a single diode PV cell and symbol of PV cell.

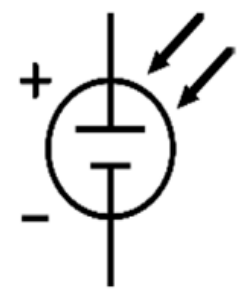

(a)

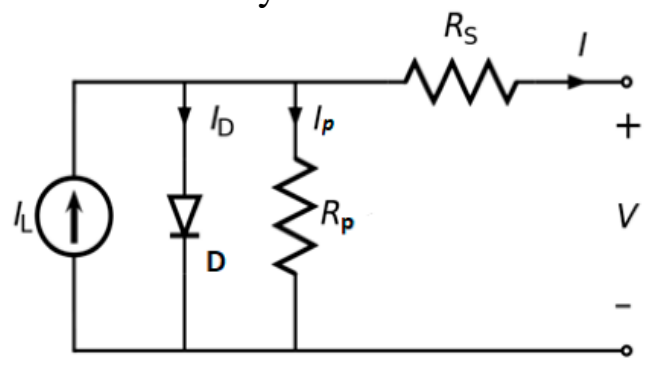

(b)

Figure 1. Modeling of solar PV cell: (a) symbol (b) equivalent circuit of a PV cell 
The mathematical representation of the solar photovoltaic cell is given by in Equation1 [11].

$$
\mathbf{I}=\mathbf{I}_{\mathbf{L}}-\mathbf{I}_{\mathbf{R S}}\left[\exp \left\{\frac{\mathbf{q}\left(\mathbf{V}+\mathbf{I R}_{\mathbf{S}}\right)}{\mathbf{V}_{\mathrm{Th}} \mathbf{a}}\right\}-\mathbf{1}\right]-\frac{\left(\mathrm{V}+\mathbf{I R}_{\mathbf{S}}\right)}{\mathbf{R}_{\mathbf{P}}}
$$

Where $\boldsymbol{V}$ and $\boldsymbol{I}$ are the solar PV cell voltage and current respectively. $\mathrm{I}_{\mathrm{L}}$ is the photo generated current of the PV module and represented as

$$
I_{L}=\frac{G}{G_{0}}\left[I_{L S T C}+K_{i s c}\left(T_{c}-T_{S T C}\right)\right]
$$

$K_{i s c}$ is the module short-circuit co-efficient. $I_{L S T C}$ is the module light generated current at standard test conditions (STC). $\mathrm{G}$ is the incident irradiation and $\mathrm{G}_{0}$ is standard irradiation. $\mathrm{T}_{\mathrm{c}}$ and $\mathrm{T}_{\mathrm{STC}}$ are the actual and STC temperatures in Kelvin.

The PV array consists of NP and Ns number of PV modules that are connected in parallel and series, respectively, is shown in Figure 2.

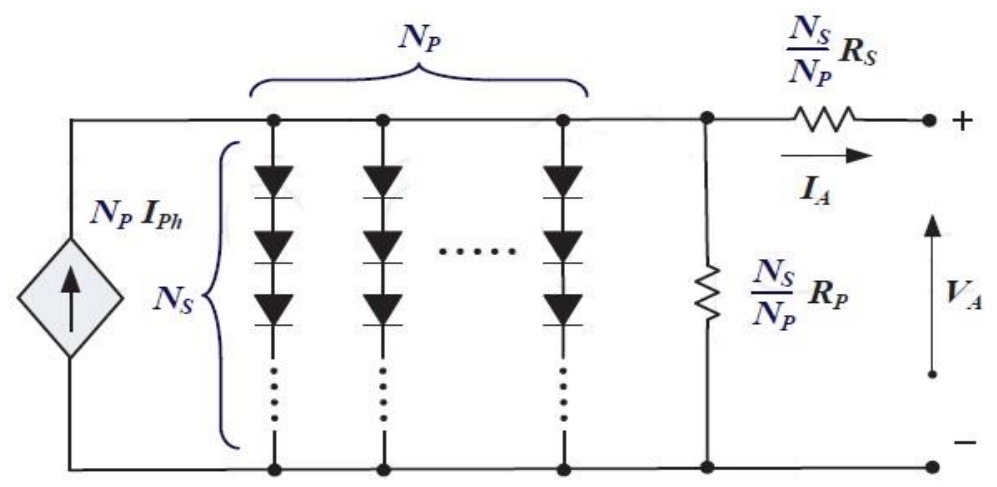

Figure 2. Solar PV array with number of modules

The PV array current is mathematically represented in Equation 3[12].

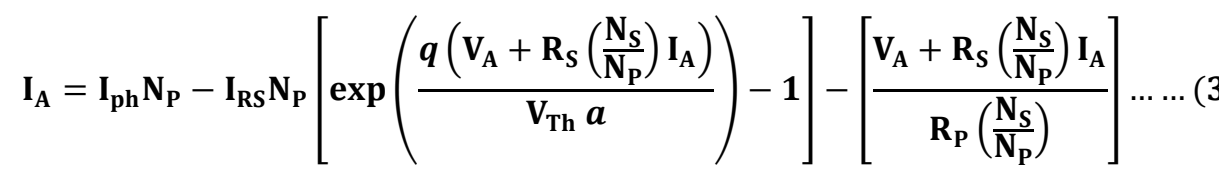

where $\mathrm{I}_{\mathrm{A}}$ : array current; $\mathrm{V}_{\mathrm{A}}$ : array voltage $[\mathrm{V}] ; \mathrm{I}_{\mathrm{ph}}$ and $\mathrm{I}_{\mathrm{RS}}$ are solar cell photo current[A] and diode reverse saturation current $[\mathrm{A}]$, respectively; $\mathrm{R}_{\mathrm{S}}$ and $\mathrm{R}_{\mathrm{P}}$ are series and parallel resistances[ $\Omega]$, respectively; A: Diode ideality factor (value 1 to 5); $\mathrm{V}_{\mathrm{Th}}$ : cell thermal voltage $[\mathrm{V}]$ as $\mathrm{V}_{\mathrm{Th}}=\mathrm{kT}$ /q; $\mathrm{T}_{\mathrm{C}}$ : solar cell absolute operating temperature $[\mathrm{K}]$; q: electron charge $\left[1.602 \times 10^{-19}\right.$ coulombs]; k: Boltzmann's constant $\left[91.38065 \mathrm{e}^{-23} \mathrm{~J} / \mathrm{K}\right]$.

The simple $6 \times 6$ size PV plant with series-parallel (SP) connection is shown in Figure 3. Each string consists of $6(\mathrm{M})$ series connection modules and connects 6 number of strings $(\mathrm{N})$ in parallel to form a SP configuration. 


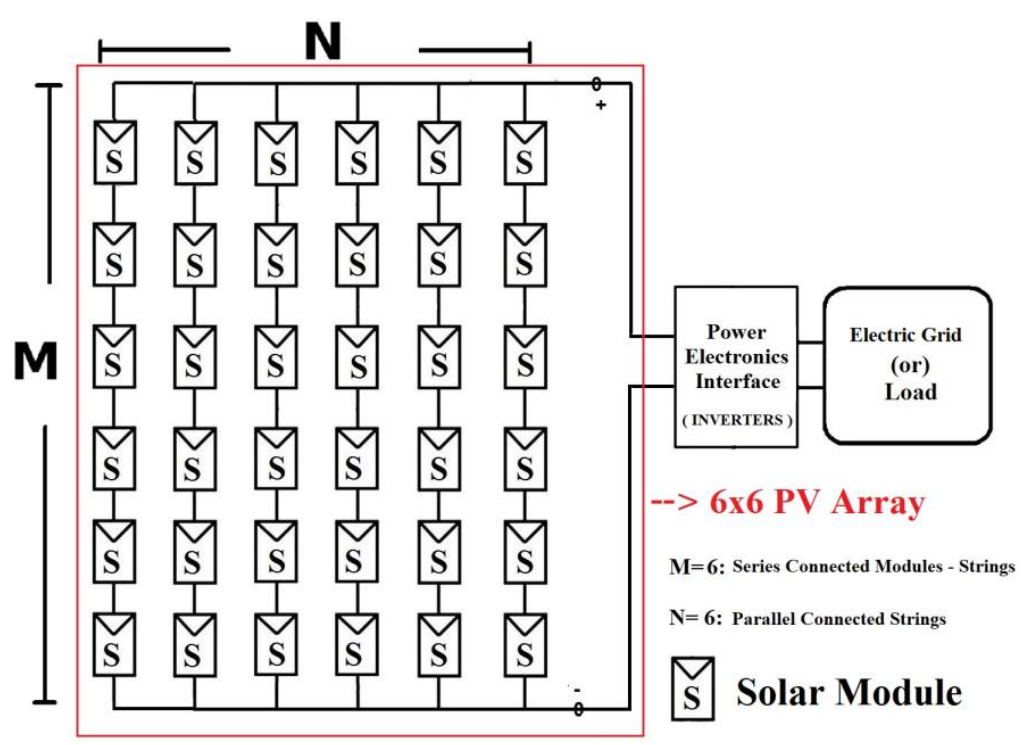

Figure 3. Simple 6 × 6 size series-parallel connection type PV Plant

Solar PV array configuration is formed by number of modules connected in parallel and series [12-13]. $V_{\mathbf{m}}$ and $I_{\mathbf{m}}$ are the un-shaded SPV module voltage and current, respectively. If the $\mathbf{n}$ number of modules are connected in series, the current through series modules is the same, but the voltage across the array is the sum of individual module voltages. In series connection, the total power is calculated by Equation 4,

$$
\left.\begin{array}{c}
I_{\text {array }}=I_{\text {string }}=I_{\mathrm{m} 1}=I_{\mathrm{m} 2}=\cdots=I_{\mathrm{mn}}=I_{\mathrm{m}} \\
V_{\text {array }}=V_{\mathrm{m} 1}+V_{\mathrm{m} 2}+V_{\mathrm{m} 3}+\cdots+V_{\mathrm{mn}}=n V_{\mathrm{m}} \\
P_{\text {array }}=n V_{m} I_{m}
\end{array}\right\}
$$

When the SPV modules are connected in parallel, the voltage across each module is the same, but the total current of array is the sum of currents of each module. In parallel connection, the total power is calculated by Equation 5,

$$
\left.\begin{array}{c}
V_{\text {array }}=V_{\mathrm{m} 1}=V_{\mathrm{m} 2}=\cdots=V_{\mathrm{mn}}=V_{\mathrm{m}} \\
I_{\text {array }}=I_{\mathrm{m} 1}+I_{\mathrm{m} 2}+\cdots+I_{\mathrm{mn}}=n I_{\mathrm{m}} \\
P_{\text {array }}=n V_{\mathrm{m}} I_{\mathrm{m}}
\end{array}\right\}
$$

The current and voltage of the SPV array for $i^{\text {th }}$ row and $j^{\text {th }}$ column $(i \times j=n)$ in array configuration are given by Equation 6.

$$
\left.\begin{array}{c}
I_{\text {array }}=j I_{\mathrm{m}} \\
V_{\text {array }}=i V_{\mathrm{m}} \\
(\mathrm{i} \times \mathrm{j}) V_{\mathrm{m}} I_{\mathrm{m}}=n V_{\mathrm{m}} I_{\mathrm{m}}
\end{array}\right\}
$$

The power will be reduced, when all modules in the SPV array configuration are uniformly shaded with shading factor $S_{\mathrm{f}}$. The array power is given by Equation 7, $P_{\text {array }}=S_{\mathrm{f}} \times n \times V_{\mathrm{m}} \times I_{\mathrm{m}}$ 


\subsection{Specifications of Solar PV Module}

In this paper, in order to model and simulate different rearranged based SPV array configurations, the Vikram Solar ELDORA 270 PV module available in MATLAB/ Simulink is considered. The PV module specifications under STC $\left(1000 \mathrm{~W} / \mathrm{m}^{2}\right.$ and $\left.25^{\circ} \mathrm{C}\right)$ are tabulated in Table 1.

Table 1. Specifications of Vikram Solar ELDORA 270 module

\begin{tabular}{llll}
\hline Parameters & & Values \\
\hline Maximum Power & & $270 \mathrm{~W}$ \\
Cells per module & $\mathrm{N}_{\text {cell }}$ & 72 \\
Open circuit voltage & $\mathrm{V}_{\mathrm{OC}}$ & $44 \mathrm{~V}$ \\
Short-circuit current & $\mathrm{I}_{\mathrm{SC}}$ & $8.1 \mathrm{~A}$ \\
Voltage at maximum power point & $\mathrm{V}_{\mathrm{MP}}$ & $34.7 \mathrm{~V}$ \\
Current at maximum power point & $\mathrm{I}_{\mathrm{MP}}$ & $7.8 \mathrm{~A}$ \\
Temperature coefficient of & $\mathrm{V}_{\mathrm{oc}}$ & $-0.3583 \% /{ }^{\circ} \mathrm{C}$ \\
Temperature coefficient of & $\mathrm{I}_{\mathrm{sc}}$ & $0.024975 \% /{ }^{\circ} \mathrm{C}$ \\
Light generated current & $\mathrm{I}_{\mathrm{L}}$ & $8.1924 \mathrm{~A}$ \\
Diode saturation current & $\mathrm{I}_{\mathrm{o}}$ & $2.4871 \mathrm{e}-10$ \\
Diode ideality factor & & 0.98223 \\
Shunt resistance & $\mathrm{R}_{\mathrm{sh}}$ & $3126.5623 \Omega$ \\
Series resistance & $\mathrm{R}_{\mathrm{s}}$ & $0.52303 \Omega$ \\
Module Area $(\mathrm{LxWxH}) \mathrm{mm}$ & & $1955 \times 982 \times 36$ \\
\hline
\end{tabular}

\subsection{Solar Photovoltaic Array Configurations}

The main conventional configurations or topologies based on type of connections of PV modules in SPV array are classified as:

a. Series (S) connection type configuration

b. Parallel (P) connection type configuration

c. Series-Parallel (S-P) connection type configuration

d. Bridge-Linked (B-L) connection type configuration

e. Honey-Comb (H-C) connection type configuration

f. Total-Cross-Tied (TCT) connection type configuration

In the series connection type, all modules are connected in series. In the parallel connection type, all modules are connected in parallel as shown in Figure 3. The S and P type of connections are not suitable for applications, because high currents exist in the parallel type and high voltages in the series type [14-15]. In the SP connection, series connected modules known as strings are connected in parallel. In the TCT type of connection, ties are connected among modules to get more power. The formation of different types of SPV array topologies from photovoltaic cell to array configurations is shown in Figure 4. 


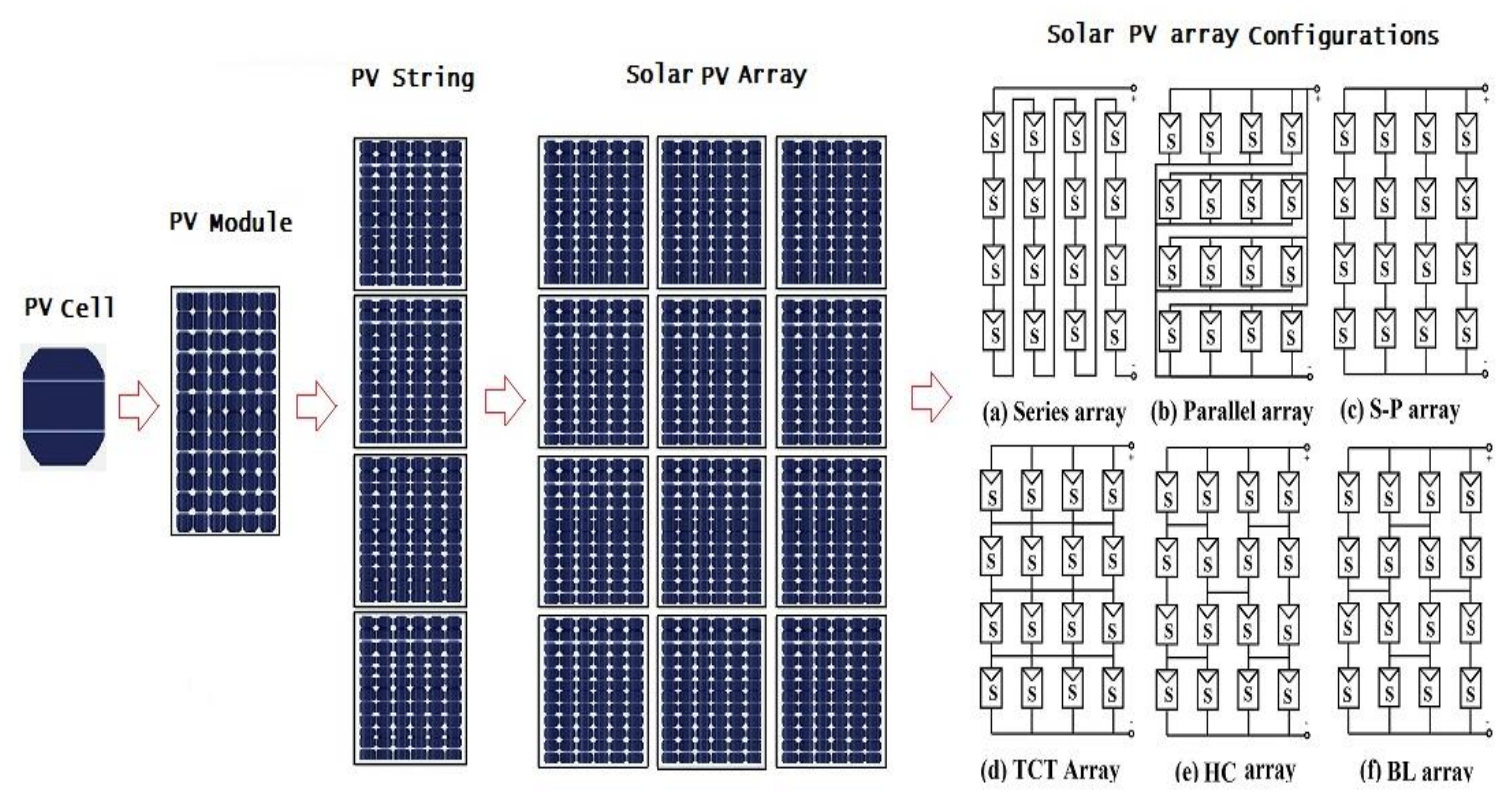

Figure 4. Formation of $4 \times 4$ size solar PV array topologies

2.4 Rearrangement of SPV modules based Total Cross Tied (TCT) configurations:

The modules in each row and column of TCT topologies are rearranged for enhancing the output power of the SPV array. Based on the rearrangement of modules, the TCT topologies are classified into,

i. Su-Do-Ku based TCT configuration

ii. Arrow Su-Do-Ku based TCT configuration

iii. Ken Ken- TCT configuration

iv. Skyscrapers- TCT configuration

v. Non-Symmetric TCT configuration

vi. Chaotic Baker Map (CBM)-TCT configuration

vii. Odd-Even TCT configuration

viii. Futoshiki - TCT configuration

ix. Latin Square-TCT configuration

x. Magic square-TCT configuration

xi. Current based (Im based) TCT configuration

xii. Voltage based (Vm based) TCT configuration

The above module re-arrangements in a $6 \times 6 \mathrm{SPV}$ array are based on the puzzle pattern arrangement. In this method, the electrical contacts of modules in the SPV array configuration are un-changed and repositioning the existing modules to new place according to puzzle-based numbers [6-10]. The performance of TCT configuration under this rearranged method is improved compared to conventional TCT configuration.

\section{Proposed Optimal Configuration}

The proposed optimal interconnection topology for the TCT array is developed from the connection switch ( $\mathrm{CS}=0$ or 1) method as explained in Section 3.1. In this proposed method, the electrical connections between modules in SPV array 
configurations are minimized. These interconnections are based on the shading pattern in the array configuration.

\section{Proposed Optimal TCT Array Configuration}

\subsection{Methodology}

In the proposed optimal interconnections among modules, the entire PV array system (any PV plant has a capacity of few $\mathrm{KW}$ to $\mathrm{MW}$ ) is sub-divided into a small $2 \times 2$ size SPV sub arrays. The simulation results of a $2 \times 2$ sub array with tie connection switch (TCS=0/1) analysis [11], i.e., if tie connection (tie) or interconnection is present means $\mathrm{TCS}=1$ or absent means TCS $=0$, among the PV modules under seven possible shading cases for irradiances $500 \mathrm{~W} / \mathrm{m}^{2}$ and $700 \mathrm{~W} / \mathrm{m}^{2}$ are tabulated in Table 2. Figure 5 shows the PV modules S1, S2, S3 and S4 of $2 \times 2$ sub array with possible shading cases [11].

In Case I, all modules receive a constant solar irradiance of $1000 \mathrm{~W} / \mathrm{m}^{2}$ and the maximum power generated with tie connection and without tie connection is $6676 \mathrm{~W}$. So, a tie connection is required. In Case II, the irradiance of module S1 is $500 \mathrm{~W} / \mathrm{m}^{2}$ and S2, $\mathrm{S} 3, \mathrm{~S} 4$ modules receive an irradiance of $1000 \mathrm{~W} / \mathrm{m}^{2}$. Under this case the array power without tie connection is less than that with tie connection, so a tie is required among modules. In Cases III, IV and V, two modules are shaded as shown in Figure-5. If the two modules are shaded in horizontal $(\mathrm{S} 1, \mathrm{~S} 2)$ or vertical $(\mathrm{S} 1, \mathrm{~S} 3)$ positions in four positions, the array output power is the same, so tie is not required. If the diagonally connected modules are shaded, a tie between the SPV modules is required for the maximum array power. In Case VI: modules S1, S2 and S3 are shaded and module S4 is un-shaded. The output power of $2 \times 2$ array with tie connection is higher than that without tie connection, so a tie is required. In Case VII: all four modules are shaded and the power of SPV array with and without tie is the same, so a tie connection is not required among the modules.

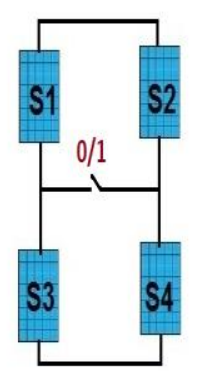

Case-I

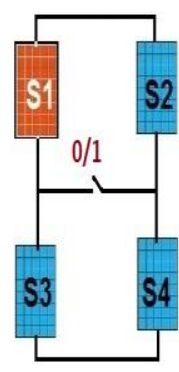

Case-II

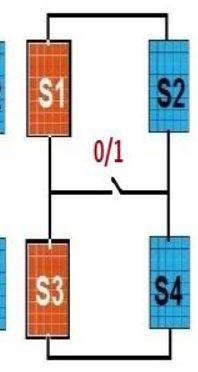

Case-III

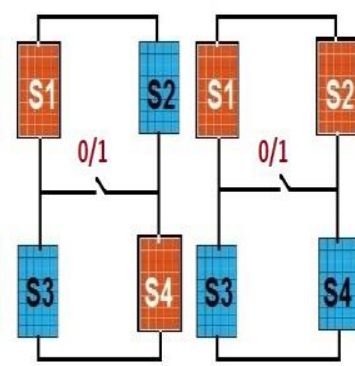

Case-IV

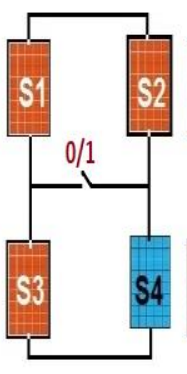

Case-VI

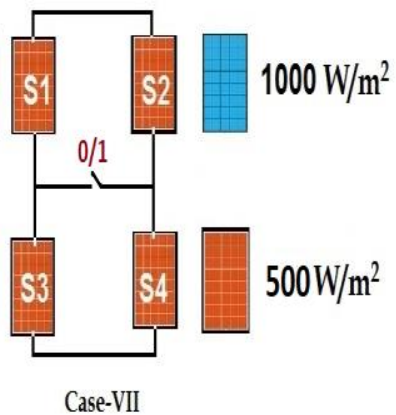

Figure 5. Possible shaded cases for $2 \times 2$ PV array

In Cases I, III, V and VII, the array power is equal in with and without the tie connection, so the tie is not required. But in Cases II, IV, VI, the global maximum power of the SPV array with a tie connection is higher than that without a tie connection. In this condition, a tie connection is required among modules for maximizing power. According to the above cases, it can be concluded that the power output of the SPV array depends on the location of number of shaded modules in an array configuration. In most cases, the requirement of a tie among SPV modules in the proposed optimal method is less and the number of electrical connections among the modules is minimized. From Table 2, it is concluded that the tie among the modules in an array is required for one shaded module, 
two diagonally shaded modules or three shaded modules cases, while the interconnection or tie is not necessary among modules for other cases.

Table 2. Maximum powers for different irradiance levels

\begin{tabular}{|c|c|c|c|c|c|c|}
\hline \multirow[t]{2}{*}{ Case } & \multirow[t]{2}{*}{ Shadow type } & \multicolumn{2}{|c|}{$\begin{array}{c}\text { Maximum Power } P_{m}(W) \text { of } \\
\text { shaded modules of irradiance } \\
500 \mathrm{~W} / \mathrm{m}^{2}\end{array}$} & \multicolumn{2}{|c|}{$\begin{array}{c}\text { Maximum Power } \mathrm{P}_{\mathrm{m}}(\mathrm{W}) \text { of } \\
\text { shaded modules of irradiance } \\
700 \mathrm{~W} / \mathrm{m}^{2}\end{array}$} & \multirow[t]{2}{*}{$\begin{array}{c}\text { Tie } \\
\text { Required } \\
\text { (Yes/No) }\end{array}$} \\
\hline & & $\mathrm{CS}=0$ & $\mathrm{CS}=1$ & $\mathrm{CS}=0$ & $\mathrm{CS}=1$ & \\
\hline I & No Shade & 1062 & 1062 & 1062 & 1062 & No \\
\hline II & One shaded module & 815 & 851.5 & 930.2 & 948.4 & Yes \\
\hline III & Two shaded modules in Series & 801.6 & 801.6 & 908.1 & 908.1 & No \\
\hline IV & Two diagonally shaded modules & 589.8 & 801.6 & 804.3 & 908.1 & Yes \\
\hline V & Two shaded modules in Parallel & 589.8 & 589.8 & 804.3 & 804.3 & No \\
\hline VI & Three Shaded module & 560.6 & 579.2 & 776.9 & 790.9 & Yes \\
\hline VII & All modules are shaded & 542.7 & 542.7 & 755.3 & 755.3 & No \\
\hline
\end{tabular}

3.2 Modeling of Optimal Interconnection Configuration for Shading Case 9 and Case 14

In this section, the modeling of $6 \times 6$ size solar PV array configurations by the proposed optimal interconnection method are presented.

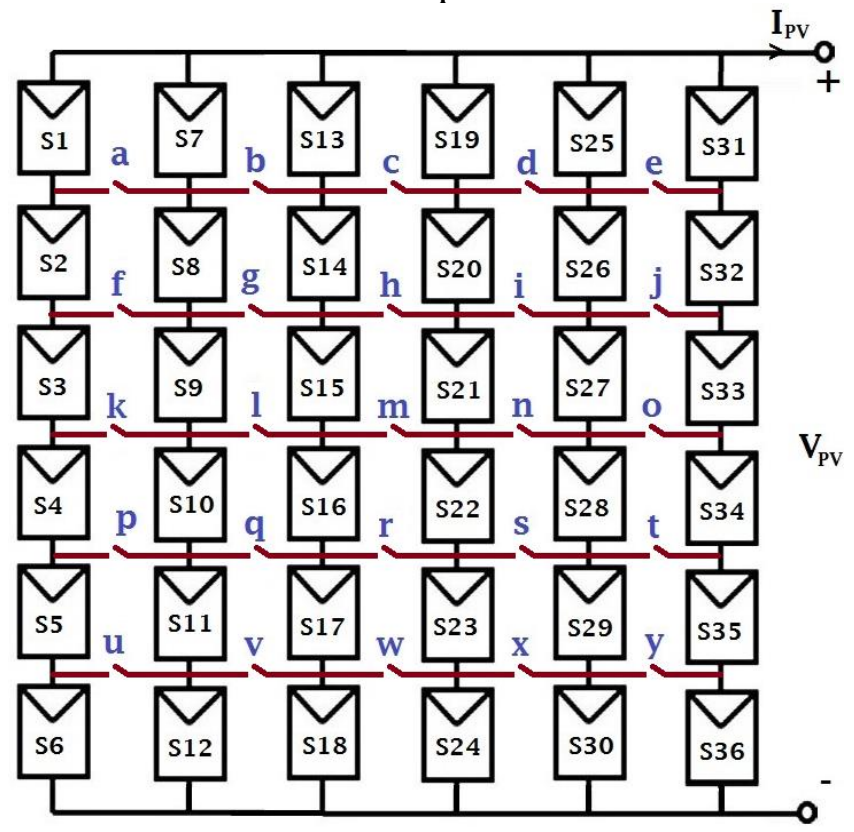

Figure 6. $6 \times 6$ size solar S-P PV array with interconnections among modules

In the proposed method, the entire $6 \times 6$ size PV array is sub-divided into a small number of $2 \times 2$ arrays, and the number of electrical connections, i.e., interconnections required for connection of modules in an array configuration, is developed with the concept of proposed tie connection switch (TCS) method as described in Figure 6 in Section 3.1. TCS $=1$ means a tie connection present and TCS $=0$ means a tie connection absent between SPV array modules. The a, b, c, d, e, f, g, h, i, j, k, l, m, n, o, p, q, r, s, t, u, $\mathrm{v}, \mathrm{w}, \mathrm{x}$ and $\mathrm{y}$ are the proposed interconnections/ties among the modules in the $6 \times 6$ size $\mathrm{PV}$ array system. The number of inter-connections required in the SP configuration is 0 , while the number of interconnects required in the TCT array configuration is a maximum 
of 25. In the proposed optimal topology, it depends on the number of shaded modules in the SPV array configuration. If the shaded modules in a $2 \times 2$ sub array are one, diagonally shaded two modules or three shaded modules, the tie/ interconnection required. In other cases, i.e., two shaded modules either horizontally shaded or vertically shaded, all four modules shaded or all four modules unshaded conditions, the tie is not required. This method reduces the wiring losses and wiring cost at the time of installation. The array output power of the proposed optimal topology is higher than that of the SP configuration and less than that of the TCT topology. By considering the wiring losses of rearranged based TCT configurations, the power output of proposed optimal configuration method is almost equal to that of the TCT configuration. The different partial shading cases ( 1 to 14 ) and uniform case-U are shown in Figure 7. The number of interconnections in SP, rearranged based TCT and optimal TCT configurations for cases 9 and 14 are tabulated in Table 3 and for all cases 1 to 14 are tabulated in Table 4 .

Table 3. Optimal interconnection results for cases 9 and 14

\begin{tabular}{|c|c|c|c|c|c|c|c|c|c|c|c|c|c|c|c|c|c|c|c|c|c|c|c|c|c|c|}
\hline \multirow[b]{2}{*}{ Configurations } & \multicolumn{26}{|c|}{ Interconnections/ Ties between PV Modules in $6 \times 6$ Array } \\
\hline & a & b & c & d & e & f & g & h & $\mathbf{i}$ & $\mathbf{j}$ & $\mathbf{k}$ & l & m & $\mathbf{n}$ & 0 & $p$ & $q$ & r & s & $t$ & $\mathbf{u}$ & $\mathbf{v}$ & $\mathbf{w}$ & $\mathbf{x}$ & y & Total \\
\hline SP & 0 & 0 & 0 & 0 & 0 & 0 & 0 & 0 & 0 & 0 & 0 & 0 & 0 & 0 & 0 & 0 & 0 & 0 & 0 & 0 & 0 & 0 & 0 & 0 & 0 & 0 \\
\hline $\begin{array}{l}\text { TCT/Sudoku/Arrow Sudoku/ Ken- } \\
\text { ken/ Skyscrapers/ NS/ CBM/Odd- } \\
\text { Even/ Futoshiki/LS/MS/ Im / Vm } \\
\text { based TCT }\end{array}$ & 1 & 1 & 1 & 1 & 1 & 1 & 1 & 1 & 1 & 1 & 1 & 1 & 1 & 1 & 1 & 1 & 1 & 1 & 1 & 1 & 1 & 1 & 1 & 1 & 1 & 25 \\
\hline Optimal TCT & & & & & & & & & & & & & & & & & & & & & & & & & & \\
\hline For Case-9 & 1 & 0 & 0 & 0 & 1 & 0 & 0 & 0 & 0 & 0 & 0 & 0 & 0 & 0 & 0 & 0 & 0 & 0 & 0 & 0 & 1 & 0 & 0 & 0 & 1 & 04 \\
\hline For Case-14 & 1 & 1 & 0 & 0 & 0 & 0 & 1 & 1 & 0 & 0 & 0 & 0 & 1 & 1 & 0 & 0 & 0 & 0 & 1 & 1 & 0 & 0 & 0 & 0 & 1 & 09 \\
\hline
\end{tabular}

Table 4. Optimal interconnection results for different cases

\begin{tabular}{|c|c|c|c|c|c|c|c|c|c|c|c|c|c|c|c|c|c|c|c|c|c|c|c|c|c|c|}
\hline \multirow[b]{2}{*}{ Cases } & \multicolumn{26}{|c|}{ Interconnections/ Ties between PV Modules in 6x6 Array } \\
\hline & $\mathbf{a}$ & b & c & d & e & f & g & $\mathbf{h}$ & $\mathbf{i}$ & $\mathbf{j}$ & $\mathbf{k}$ & $\mathbf{l}$ & $\mathbf{m}$ & $\mathbf{n}$ & $\mathbf{0}$ & p & q & $\mathbf{r}$ & $\mathbf{s}$ & $\mathbf{t}$ & $\mathbf{u}$ & $\mathbf{v}$ & $\mathbf{w}$ & $\mathbf{x}$ & $\mathbf{y}$ & Total \\
\hline $\mathbf{U}$ & 0 & 0 & 0 & 0 & 0 & 0 & 0 & 0 & 0 & 0 & 0 & 0 & 0 & 0 & 0 & 0 & 0 & 0 & 0 & 0 & 0 & 0 & 0 & 0 & 0 & $\mathbf{0}$ \\
\hline 1 & 0 & 0 & 0 & 0 & 0 & 0 & 0 & 0 & 0 & 0 & 0 & 0 & 0 & 0 & 0 & 0 & 0 & 0 & 0 & 0 & 0 & 0 & 0 & 0 & 0 & 0 \\
\hline 2 & 0 & 0 & 0 & 0 & 0 & 0 & 0 & 0 & 0 & 0 & 0 & 0 & 0 & 0 & 0 & 0 & 0 & 0 & 0 & 0 & 0 & 0 & 0 & 0 & 0 & 0 \\
\hline 3 & 0 & 1 & 1 & 1 & 0 & 1 & 0 & 1 & 1 & 1 & 1 & 1 & 0 & 0 & 0 & 0 & 1 & 1 & 1 & 1 & 1 & 1 & 1 & 1 & 0 & 17 \\
\hline 4 & 1 & 1 & 0 & 0 & 0 & 1 & 1 & 1 & 0 & 0 & 0 & 1 & 1 & 1 & 0 & 0 & 0 & 1 & 1 & 1 & 0 & 0 & 0 & 1 & 1 & 13 \\
\hline 5 & 0 & 0 & 0 & 0 & 0 & 1 & 1 & 0 & 0 & 0 & 1 & 0 & 0 & 0 & 0 & 0 & 0 & 0 & 0 & 0 & 0 & 0 & 0 & 0 & 0 & 03 \\
\hline 6 & 0 & 0 & 0 & 0 & 0 & 0 & 1 & 1 & 0 & 0 & 0 & 0 & 0 & 0 & 0 & 0 & 0 & 0 & 0 & 0 & 0 & 1 & 0 & 0 & 0 & 03 \\
\hline 7 & 0 & 0 & 0 & 0 & 0 & 0 & 0 & 0 & 0 & 0 & 0 & 1 & 0 & 0 & 0 & 0 & 1 & 0 & 0 & 0 & 0 & 0 & 0 & 0 & 0 & 02 \\
\hline 8 & 0 & 0 & 0 & 0 & 0 & 0 & 0 & 0 & 0 & 0 & 0 & 1 & 0 & 0 & 0 & 0 & 0 & 0 & 0 & 0 & 0 & 0 & 0 & 0 & 0 & 01 \\
\hline 9 & 1 & 0 & 0 & 0 & 1 & 0 & 0 & 0 & 0 & 0 & 0 & 0 & 0 & 0 & 0 & 0 & 0 & 0 & 0 & 0 & 1 & 0 & 0 & 0 & 1 & 04 \\
\hline 10 & 1 & 0 & 0 & 0 & 1 & 0 & 0 & 0 & 0 & 0 & 0 & 0 & 0 & 0 & 0 & 0 & 0 & 0 & 0 & 0 & 1 & 0 & 0 & 0 & 1 & 04 \\
\hline 11 & 0 & 0 & 0 & 0 & 0 & 0 & 0 & 0 & 0 & 0 & 0 & 0 & 0 & 0 & 0 & 0 & 0 & 0 & 0 & 0 & 0 & 0 & 0 & 0 & 0 & 0 \\
\hline 12 & 1 & 1 & 0 & 1 & 1 & 1 & 1 & 0 & 1 & 1 & 0 & 0 & 0 & 0 & 0 & 1 & 1 & 0 & 1 & 1 & 1 & 1 & 0 & 1 & 1 & 16 \\
\hline 13 & 1 & 0 & 0 & 0 & 0 & 0 & 0 & 0 & 0 & 0 & 0 & 0 & 0 & 0 & 0 & 0 & 0 & 0 & 0 & 0 & 0 & 0 & 0 & 0 & 0 & 01 \\
\hline 14 & 1 & 1 & 0 & 0 & 0 & 0 & 1 & 1 & 0 & 0 & 0 & 0 & 1 & 1 & 0 & 0 & 0 & 0 & 1 & 1 & 0 & 0 & 0 & 0 & 1 & 09 \\
\hline
\end{tabular}

\subsection{Partial Shaded Photovoltaic Array}

The irradiance received by an SPV array is less than $1000 \mathrm{~W} / \mathrm{m}^{2}$, i.e., nonuniform irradiance due to the shading effect. The main reason for shading is due to changes in tilt angles of modules, shading nearby buildings, clouds, bird litters, falling tree leaves on modules, and dust formed on modules because of pollution. In this work, for the performance analysis of $6 \times 6$ size re-arrangement based TCT SPV array configurations and proposed optimal TCT configurations, total fourteen partial shading 
scenarios and one uniform case- $U$ are considered, and the results including global maximum peak array power, shading losses, fill-factor, efficiency and number of ties required among modules in SPV array configurations are compared. Figure 7 shows the different irradiance values for partial shaded photovoltaic array for cases 1 to 14 .

\begin{tabular}{|c|c|c|c|c|c|}
\hline S & S & S & S & S & S \\
\hline S & S & S & S & S & S \\
\hline S & S & S & S & S & S \\
\hline S & S & S & S & S & S \\
\hline S & S & S & S & S & S \\
\hline S5 & S5 & S5 & S5 & S5 & S5 \\
\hline
\end{tabular}

Case-1

\begin{tabular}{|c|c|c|c|c|c|}
\hline S5 & S5 & $S$ & $S$ & $S$ & $S$ \\
\hline S5 & S5 & $S$ & $S$ & $S$ & $S$ \\
\hline S5 & $S$ & $S$ & $S$ & $S$ & $S$ \\
\hline$S$ & $S$ & $S$ & $S$ & $S$ & $S$ \\
\hline$S$ & $S$ & $S$ & $S$ & $S$ & $S$ \\
\hline$S$ & $S$ & $S$ & $S$ & $S$ & $S$ \\
\hline
\end{tabular}

\begin{tabular}{|c|c|c|c|c|c|}
\hline S & S & S & S & S & S \\
\hline S & S5 & S5 & S5 & S5 & S \\
\hline S & S5 & S5 & S5 & S5 & S \\
\hline S & S5 & S5 & S5 & S5 & S \\
\hline S & S5 & S5 & S5 & S5 & S \\
\hline S & S & S & S & S & S \\
\hline \multicolumn{6}{|c}{ Case-9 }
\end{tabular}

\begin{tabular}{|c|c|c|c|c|c|}
\hline S5 & S & S & S & S & S \\
\hline S & S & S & S & S & S \\
\hline S & S & S & S & S & S \\
\hline S & S & S & S & S & S \\
\hline S & S & S & S & S & S \\
\hline S & S & S & S & S & S \\
\hline
\end{tabular}

Case-13

\begin{tabular}{|l|l|l|l|l|l|}
\hline S5 & S & S & S & S & S \\
\hline S5 & S & S & S & S & S \\
\hline S5 & S & S & S & S & S \\
\hline S5 & S & S & S & S & S \\
\hline S5 & S & S & S & S & S \\
\hline S5 & S & S & S & S & S \\
\hline
\end{tabular}

Case-2

\begin{tabular}{|c|c|c|c|c|c|}
\hline S5 & S5 & S5 & S & S & S \\
\hline S5 & S5 & S5 & S & S & S \\
\hline S5 & S5 & S & S & S & S \\
\hline S5 & S5 & S & S & S & S \\
\hline S5 & S5 & S & S & S & S \\
\hline S & S & S & S & S & S \\
\hline \multicolumn{7}{|c}{ Case-6 }
\end{tabular}

\begin{tabular}{|c|c|c|c|c|c|}
\hline S5 & S5 & S5 & S5 & S5 & S5 \\
\hline S5 & S & S & S & S & S5 \\
\hline S5 & S & S & S & S & S5 \\
\hline S5 & S & S & S & S & S5 \\
\hline S5 & S & S & S & S & S5 \\
\hline S5 & S5 & S5 & S5 & S5 & S5 \\
\hline \multicolumn{6}{|c|}{ Case- -10}
\end{tabular}

\begin{tabular}{|c|c|c|c|c|c|}
\hline S5 & S & S & S & S & S \\
\hline S5 & S5 & S & S & S & S \\
\hline S5 & S5 & S5 & S & S & S \\
\hline S5 & S5 & S5 & S5 & S & S \\
\hline S5 & S5 & S5 & S5 & S5 & S \\
\hline S5 & S5 & S5 & S5 & S5 & S5 \\
\hline
\end{tabular}

Case-14

\begin{tabular}{|c|c|c|c|c|c|}
\hline S5 & S & S5 & S & S5 & S5 \\
\hline S5 & S & S & S5 & S & S \\
\hline S & S5 & S5 & S & S5 & S \\
\hline S5 & S & S5 & S & S5 & S \\
\hline S5 & S & S & S5 & S & S \\
\hline S & S & S5 & S & S & S \\
\hline
\end{tabular}

Case-3

\begin{tabular}{|c|c|c|c|c|c|}
\hline S & S & S & S & S & S \\
\hline S & S & S & S & S & S \\
\hline S & S & S & S & S & S \\
\hline S5 & S5 & S & S & S & S \\
\hline S5 & S5 & S5 & S5 & S5 & S5 \\
\hline S5 & S5 & S5 & S5 & S5 & S5 \\
\hline \multicolumn{6}{|c}{ Case-7 } \\
\hline
\end{tabular}

\begin{tabular}{|c|c|c|c|c|c|}
\hline S & S1 & S7 & S & S7 & S1 \\
\hline S7 & S2 & S8 & S7 & S2 & S8 \\
\hline S8 & S7 & S3 & S3 & S8 & S9 \\
\hline S9 & S8 & S4 & S4 & S1 & S7 \\
\hline S1 & S5 & S9 & S8 & S5 & S \\
\hline S6 & S9 & S1 & S9 & S9 & S6 \\
\hline \multicolumn{7}{|c}{ Case-11 } \\
\hline
\end{tabular}

\begin{tabular}{|l|l|l|l|l|l|}
\hline S & S & S & S & S & S \\
\hline S & S & S & S & S & S \\
\hline S & S & S & S & S & S \\
\hline S & S & S & S & S & S \\
\hline S & S & S & S & S & S \\
\hline S & S & S & S & S & S \\
\hline
\end{tabular}

\begin{tabular}{|c|c|c|c|c|c|}
\hline S5 & S & S & S & S & S \\
\hline S & S5 & S & S & S & S \\
\hline S & S & S5 & S & S & S \\
\hline S & S & S & S5 & S & S \\
\hline S & S & S & S & S5 & S \\
\hline S & S & S & S & S & S5 \\
\hline
\end{tabular}

Case-4

\begin{tabular}{|c|c|c|c|c|c|}
\hline S5 & S5 & S & S & S & S \\
\hline S5 & S5 & S & S & S & S \\
\hline S5 & S5 & S & S & S & S \\
\hline S5 & S5 & S5 & S5 & S5 & S5 \\
\hline S5 & S5 & S5 & S5 & S5 & S5 \\
\hline S5 & S5 & S5 & S5 & S5 & S5 \\
\hline \multicolumn{7}{|c}{ Case- 8} \\
\hline
\end{tabular}

\begin{tabular}{|c|c|c|c|c|c|}
\hline S5 & $S$ & $S$ & $S$ & $S$ & S5 \\
\hline$S$ & S5 & $S$ & $S$ & S5 & \\
\hline$S$ & $S$ & S5 & S5 & $S$ & $S$ \\
\hline$S$ & $S$ & S5 & S5 & $S$ & $S$ \\
\hline$S$ & S5 & $S$ & $S$ & S5 & $S$ \\
\hline S5 & $S$ & $S$ & $S$ & $S$ & S5 \\
\hline
\end{tabular}

\begin{tabular}{|ll|}
\hline \multicolumn{2}{|c|}{ Solar Irradiance $\left(\mathrm{W} / \mathrm{m}^{2}\right):$} \\
\hline $\mathrm{S} 1=100$ & $\mathrm{~S} 6=600$ \\
$\mathrm{~S} 2=200$ & $\mathrm{~S} 7=700$ \\
$\mathrm{~S} 3=300$ & $\mathrm{~S} 8=800$ \\
$\mathrm{~S} 4=400$ & $\mathrm{~S} 9=900$ \\
$\mathrm{~S} 5=500$ & $\mathrm{~S}=1000$ \\
\hline
\end{tabular}

Figure 7. Proposed partial shading cases for $6 \times 6$ SPV TCT array configurations

\section{Modeling and Simulation of Re-arrangement of Solar PV Modules Based TCT Configurations}

\subsection{Rearrangement of Modules in 6×6 TCT Solar PV Array}

As shown in Figure 8, the photovoltaic modules are arranged in row and column wise for a $6 \times 6$ size conventional TCT array configuration. The number 11 indicates $1^{\text {st }}$ row and $1^{\text {st }}$ column, 12 indicates $1^{\text {st }}$ row and $2^{\text {nd }}$ column and similarly for 66 means $6^{\text {th }}$ row and $6^{\text {th }}$ column. In SP,TCT and optimal TCT type of configurations the modules doesn't change their positions in an SPV array, whereas in remaining rearranged based TCT array configurations the position of modules is rearranged based on the puzzle number pattern. In this rearrangement module-based configurations, the modules in every column or row are changed to other columns or rows in the entire $6 \times 6$ size array depending on the type of puzzle used. As shown in Figure 9, the rearrangement of modules is based on the puzzle number patterns, including Sudoku, Arrow Sudoku, Ken- 
Ken type, skyscrapers type, Non-symmetric, CBM, Odd-Even, Futoshiki, Latin Square, Magic Square, Im based (current based arrangement) and Vm based (voltage based arrangement) method [15-16]. For the Im based method, let's consider a $6 \times 6$ TCT array with 36 modules which are rearranged by Im values of SPV module as shown in Figure 9. In the proposed rearrangement method, only modules are rearranged in different rows or columns without altering the electrical connections of SPV array configurations. So, the shade will be dispersed to a new row or column in the array. It improves the performance of photovoltaic array configurations, compared to other conventional configurations. In this rearrangement-based configuration, the performance will be improved but it requires more wires for repositioning of modules to a new row or column in an array. It leads to wiring losses and increases the installation cost of the solar plant. The rearrangement of modules based on Sudoku puzzle for TCT configuration is shown in Figure 8. In a similar way, remaining SPV TCT array configurations are rearranged based on puzzle patterns shown in Figure 9.

In the Series-Parallel configuration, series connection of modules (strings) are connected in parallel shown in Figure 4(c). The TCT array topology is formed from interconnecting the rows of the junction of SP scheme through ties. In the optimal TCT configuration type, ties are connected between modules, depending on the number of shaded modules and their locations in an array configuration. In Sudoku, Arrow Sudoku, Ken-Ken, Non-symmetric and Latin square type, modules in $1^{\text {st }}$ column are unchanged, while the positions of $2^{\text {nd }}, 3^{\text {rd }}, 4^{\text {th }}, 5^{\text {th }}$ and $6^{\text {th }}$ column modules are changed and based on the puzzle pattern. In skyscraper, CBM, Odd-Even and Futoshiki type of TCT array configurations, all modules in each row and column are changed to the new optimal location in an array according to puzzle arrangement shown in Figure 9.

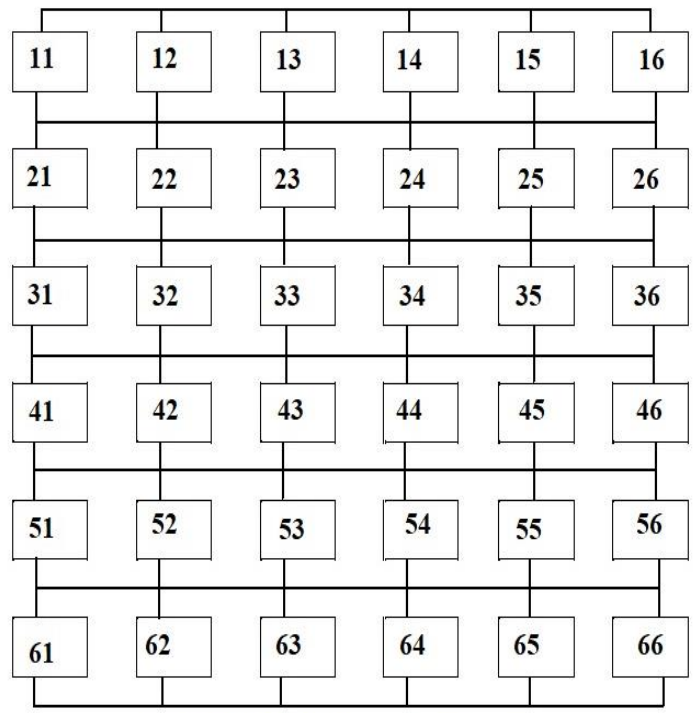

(a) 6x6 TCT PV Array Configuration

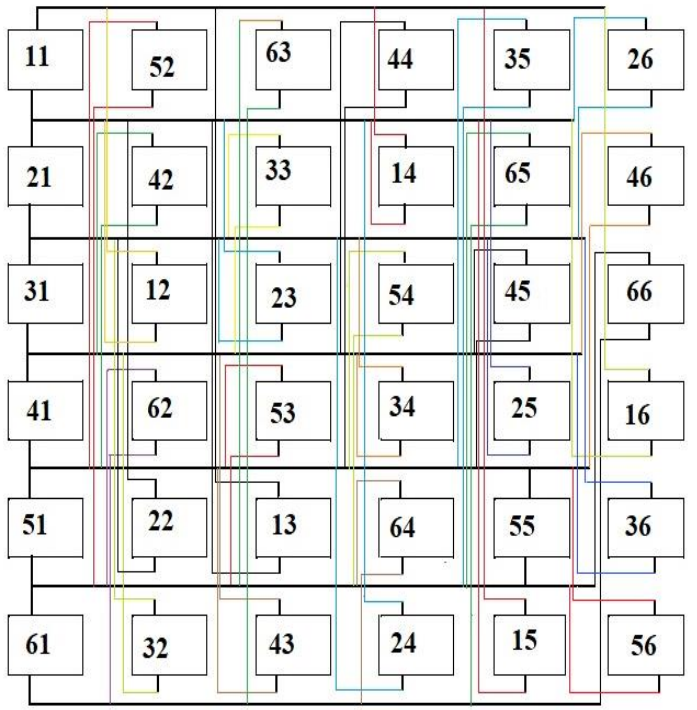

(b) 6x6 SuDoKu based Re-arranged TCT Configuration

Figure 8. Proposed Su-Do-Ku puzzle based re-arranged TCT SPV array configuration 


Series-Parallel
\begin{tabular}{|l|l|l|l|l|l|}
\hline 11 & 12 & 13 & 14 & 15 & 16 \\
\hline 21 & 22 & 23 & 24 & 25 & 26 \\
\hline 31 & 32 & 33 & 34 & 35 & 36 \\
\hline 41 & 42 & 43 & 44 & 45 & 46 \\
\hline 51 & 52 & 53 & 54 & 55 & 56 \\
\hline 61 & 62 & 63 & 64 & 65 & 66 \\
\hline
\end{tabular}

Arrow Sudoku-TCT

\begin{tabular}{|l|l|l|l|l|l|}
\hline 11 & 52 & 63 & 24 & 45 & 36 \\
\hline 31 & 22 & 13 & 44 & 65 & 56 \\
\hline 41 & 62 & 33 & 54 & 15 & 26 \\
\hline 51 & 42 & 23 & 14 & 35 & 66 \\
\hline 61 & 12 & 53 & 34 & 25 & 46 \\
\hline 21 & 32 & 43 & 64 & 55 & 16 \\
\hline
\end{tabular}

Chaotic baker Map (CBM)-TCT

\begin{tabular}{|l|l|l|l|l|l|}
\hline 35 & 25 & 15 & 36 & 26 & 16 \\
\hline
\end{tabular} \begin{tabular}{|l|l|l|l|l|l|}
\hline 65 & 55 & 45 & 66 & 56 & 46 \\
\hline
\end{tabular}

\begin{tabular}{|l|l|l|l|l|l|}
\hline 64 & 54 & 44 & 34 & 24 & 14 \\
\hline
\end{tabular}

\begin{tabular}{|l|l|l|l|l|l|}
\hline 21 & 11 & 22 & 12 & 23 & 13 \\
\hline
\end{tabular}

\begin{tabular}{|lllllll|l|}
\hline 41 & 31 & 42 & 32 & 43 & 33 \\
\hline
\end{tabular}

\begin{tabular}{|l|l|l|l|l|l|}
\hline 61 & 51 & 62 & 52 & 63 & 53 \\
\hline
\end{tabular}

Total-Cross-Tied (TCT)
\begin{tabular}{|l|l|l|l|l|l|}
\hline 11 & 12 & 13 & 14 & 15 & 16 \\
\hline 21 & 22 & 23 & 24 & 25 & 26 \\
\hline 31 & 32 & 33 & 34 & 35 & 36 \\
\hline 41 & 42 & 43 & 44 & 45 & 46 \\
\hline 51 & 52 & 53 & 54 & 55 & 56 \\
\hline 61 & 62 & 63 & 64 & 65 & 66 \\
\hline
\end{tabular}

Ken Ken-TCT

\begin{tabular}{|l|l|l|l|l|l|}
\hline 11 & 42 & 63 & 34 & 55 & 26 \\
\hline 21 & 52 & 13 & 44 & 65 & 36 \\
\hline 31 & 62 & 23 & 54 & 15 & 46 \\
\hline 41 & 12 & 33 & 64 & 25 & 56 \\
\hline 51 & 22 & 43 & 14 & 35 & 66 \\
\hline 61 & 32 & 53 & 24 & 45 & 16 \\
\hline
\end{tabular}

\begin{tabular}{|l|l|l|l|l|l|}
\hline 11 & 13 & 15 & 31 & 33 & 35 \\
\hline 51 & 53 & 55 & 22 & 24 & 26 \\
\hline 42 & 44 & 46 & 62 & 64 & 66 \\
\hline 12 & 14 & 16 & 32 & 34 & 36 \\
\hline 52 & 54 & 56 & 21 & 23 & 25 \\
\hline 41 & 43 & 45 & 61 & 63 & 65 \\
\hline
\end{tabular}

Magic Square (MS)- TCT
\begin{tabular}{|c|c|c|c|c|c|}
\hline 11 & 56 & 46 & 31 & 26 & 61 \\
\hline 65 & 22 & 45 & 35 & 52 & 12 \\
\hline 64 & 54 & 33 & 43 & 23 & 14 \\
\hline 13 & 53 & 34 & 44 & 24 & 63 \\
\hline 62 & 25 & 32 & 42 & 55 & 15 \\
\hline 16 & 21 & 41 & 36 & 51 & 66 \\
\hline
\end{tabular}

ODD-EVEN TCT

Im based TCT

Im based TCT
\begin{tabular}{|l|l|l|l|l|l|}
\hline 11 & 62 & 13 & 64 & 15 & 66 \\
\hline 21 & 52 & 23 & 54 & 25 & 56 \\
\hline 31 & 42 & 33 & 44 & 35 & 46 \\
\hline 41 & 32 & 43 & 34 & 45 & 36 \\
\hline 51 & 22 & 53 & 24 & 55 & 26 \\
\hline 61 & 12 & 63 & 14 & 65 & 16 \\
\hline
\end{tabular}

Im based TCT

\begin{tabular}{|l|l|l|l|l|l|}
\hline 11 & 16 & 12 & 15 & 13 & 14 \\
\hline 66 & 61 & 65 & 62 & 64 & 63 \\
\hline 21 & 26 & 22 & 25 & 23 & 24 \\
\hline 56 & 51 & 55 & 52 & 54 & 53 \\
\hline 31 & 36 & 32 & 35 & 33 & 34 \\
\hline 46 & 41 & 45 & 42 & 44 & 43 \\
\hline
\end{tabular}

Futoshiki-TCT

\begin{tabular}{|l|l|l|l|l|l|}
\hline 61 & 52 & 43 & 14 & 25 & 36 \\
\hline 31 & 62 & 53 & 44 & 15 & 26 \\
\hline 21 & 32 & 63 & 54 & 45 & 16 \\
\hline 11 & 22 & 33 & 64 & 55 & 46 \\
\hline 41 & 12 & 23 & 34 & 65 & 56 \\
\hline 51 & 42 & 13 & 24 & 35 & 66 \\
\hline
\end{tabular}

Latin Square (LS)-TCT

\begin{tabular}{|l|l|l|l|l|l|}
\hline 11 & 62 & 53 & 44 & 35 & 26 \\
\hline 21 & 12 & 63 & 54 & 45 & 36 \\
\hline 31 & 22 & 13 & 64 & 55 & 46 \\
\hline 41 & 32 & 23 & 14 & 65 & 56 \\
\hline 51 & 42 & 33 & 24 & 15 & 66 \\
\hline 61 & 52 & 43 & 34 & 25 & 16 \\
\hline
\end{tabular}

Elements mn means -> $m^{\text {th }}$ row $\& n^{\text {th }}$ column

Example:

$11 \rightarrow 1^{\text {st }}$ row $1^{\text {st }}$ column $61->6^{\text {th }}$ row $1^{\text {st }}$ column

Figure 9. Rearrangement of modules in TCT SPV array Configurations based on puzzle patterns

\subsection{Shade Dispersion Analysis of Su-Do-Ku Puzzle Based TCT SPV Array Configuration}

Figure 10 shows the shade dispersion analysis for the Sudoku puzzle based TCT configuration. As shown in Figure 10(a), a 6×6 size TCT PV array consists of 6 rows and 6 columns of modules. In this method, the PV modules are repositioned in each row and column based on puzzle patterns without altering electrical connections. These electrical interconnections are the same as that of the TCT array topology. The module arrangement in Sudoku pattern is shown in Figure 10(b). The modules in the $1^{\text {st }}$ column remain unchanged and modules in remaining five columns are changed their positions as shown in Figure 10(c). For the $5^{\text {th }}$ row of the TCT array configuration that is completely shaded, the modules are repositioned to new optimal location in a same column by rearrangement of modules based on Sudoku puzzle. In the Sudoku arrangement, the modules are re-arranged to a new position, compare to previous positions as shown in Figure 10(a). In this arrangement, the position of the shaded modules is changed, and the shade will be dispersed to a new position, as shown in Figure 10(d) of shade dispersion with Sudoku-TCT configuration. By this shade dispersion technique, the shading on the TCT array configuration is dispersed without altering the electrical connections by simply repositioning of existing modules in an array, and it improves the output power of array as compared to the conventional TCT configuration. 


\begin{tabular}{|l|l|l|l|l|l|}
\hline 11 & 12 & 13 & 14 & 15 & 16 \\
\hline 21 & 22 & 23 & 24 & 25 & 26 \\
\hline 31 & 32 & 33 & 34 & 35 & 36 \\
\hline 41 & 42 & 43 & 44 & 45 & 46 \\
\hline 51 & 52 & 53 & 54 & 55 & 56 \\
\hline$\underline{61}$ & $\underline{62}$ & $\underline{63}$ & $\underline{64}$ & $\underline{65}$ & $\underline{66}$ \\
\hline
\end{tabular}

(a) Total-Cross-Tied (TCT)

\begin{tabular}{|l|l|l|l|l|l|}
\hline 1 & 5 & 6 & 4 & 3 & 2 \\
\hline 2 & 4 & 3 & 1 & 6 & 4 \\
\hline 3 & 1 & 2 & 5 & 4 & 6 \\
\hline 4 & 6 & 5 & 3 & 2 & 1 \\
\hline 5 & 2 & 1 & 6 & 5 & 3 \\
\hline 6 & 3 & 4 & 2 & 1 & 5 \\
\hline
\end{tabular}

(b) Su-Do-Ku Pattern

\begin{tabular}{|l|l|l|l|l|l|}
\hline 11 & 52 & 63 & 44 & 35 & 26 \\
\hline 21 & 42 & 33 & 14 & 65 & 46 \\
\hline 31 & 12 & 23 & 54 & 45 & 66 \\
\hline 41 & 62 & 53 & 34 & 25 & 16 \\
\hline 51 & 22 & 13 & 64 & 55 & 36 \\
\hline 61 & 32 & 43 & 24 & 15 & 56 \\
\hline
\end{tabular}

(c) Su-Do-Ku Arrangement

\begin{tabular}{|l|l|l|l|l|l|}
\hline 11 & 12 & 13 & 14 & $\underline{15}$ & 16 \\
\hline 21 & 22 & 23 & 24 & 25 & 26 \\
\hline 31 & 32 & 33 & 34 & 35 & 36 \\
\hline 41 & 42 & 43 & 44 & 45 & 46 \\
\hline 51 & 52 & 53 & 54 & 55 & 56 \\
\hline 61 & 62 & 63 & 64 & 65 & 66 \\
\hline
\end{tabular}

(d) Shade Dispersion: Sudoku-TCT

Figure 10. Su-Do-Ku based TCT configuration with shade dispersion technique

\subsection{Performance of Rearrangement Modules Based TCT SPV Array Configuration}

This section describes the comprehensive study on SP, TCT, optimal TCT and puzzle-based rearrangement of TCT array configurations [8-10] under one uniform case$\mathrm{U}$ and 14 number of shading scenarios (Cases 1-14). The proposed optimal interconnection technique is applicable for PV systems of any size, improves the array power, and requires a minimum number of ties and low shading losses, compared to SP and TCT configurations. This optimal method doesn't require any switches or sensors, so it is simple to implement [9-13].

The interconnections or ties among modules are a, b, c, d, e, f, g, h, i, j, k, l, m, n, $\mathrm{o}, \mathrm{p}, \mathrm{q}, \mathrm{r}, \mathrm{s}, \mathrm{t}, \mathrm{u}, \mathrm{v}, \mathrm{w}, \mathrm{x}$ and $\mathrm{y}$, as shown in Figure 6. For SP configurations, no tie connections are required, and in puzzle based rearranged TCT configurations, a total 25 ties are required among modules. In the case of the proposed optimal configuration, only a smaller number of ties is required, which depends on the shading pattern. In this proposed optimal method, the mismatch losses given in Equation 8 are reduced compared to the series-parallel configuration, and the number of interconnections or ties are minimized compared to the TCT array configuration. It also reduces the installation time, cost, cable losses, and wiring required for installation of PV system.

Mismatch power loss $\boldsymbol{P}_{\boldsymbol{m} m l o s s}(\boldsymbol{W})=\boldsymbol{P}_{\boldsymbol{m} \boldsymbol{u}}-\boldsymbol{P}_{\boldsymbol{m p s c}}$

$\%$ Power loss $=\frac{\boldsymbol{P}_{\boldsymbol{m u}}-\boldsymbol{P}_{\boldsymbol{m} p s c}}{\boldsymbol{P}_{\boldsymbol{m} u}} \times \mathbf{1 0 0}$

Fill-Factor $(\mathrm{FF})=\frac{V_{m p p} * I_{m p p}}{V_{o c} * I_{s c}}$

Efficiency, $\eta=\frac{V_{m p} * I_{m p}}{P_{i n}} \times \mathbf{1 0 0}$

Where $P_{\text {in }}=$ Number of SPV modules $\times$ Area of Module, and Area of module $=1952 \times 982$ mm (given in Table 1: specifications of solar ELDORA 270W PV module). $\boldsymbol{P}_{\boldsymbol{m} u}$ is the global maximum power (GMPP) of the SPV array at uniform irradiation of $1000 \mathrm{~W} / \mathrm{m}^{2}$ and $\boldsymbol{P}_{\boldsymbol{m} \boldsymbol{s} \boldsymbol{c}}$ is the array power at different shading cases. $\boldsymbol{V}_{\boldsymbol{m} \boldsymbol{p}}$ is the maximum voltage and $\boldsymbol{I}_{\boldsymbol{m} \boldsymbol{p}}$ is the current at maximum power point. $\boldsymbol{V}_{\boldsymbol{o c}}$ and $\boldsymbol{I}_{\boldsymbol{s c}}$ are open circuit voltage and short circuit currents of the SPV module, respectively [11-15].

\section{Wiring Losses for Solar PV Array Configurations}

The repositioning of modules to the optimal location within an array increases the distance of wiring requirement for electrical connections of modules in each column in an array configuration. So, the wire resistance is increased, which causes a wiring loss and 
increases the voltage drop. The additional length of wires required for each module depends on the physical location of the previous and next modules in the same column. Compared to the optimal interconnections of the TCT configuration under different partial shading conditions, it increases the wiring losses in a rearrangement based TCT array configuration. If the connections or ties among modules in an array are less, the wiring requirement for the PV system installation can be reduced. But in the TCT array configuration, the number of ties or interconnections among modules are more, so the wiring requirement is more. In the TCT type of configuration system, the cost of the installation increases and wiring losses are more due to the additional length of wires used for interconnection among modules in array configuration.

\section{Results and Discussion}

The output PV (Power-Voltage) characteristics of SP, proposed rearranged based TCT and proposed optimal topology under 14 different shading and one un-shaded are shown in Figures 11 to 25. The global maximum powers of the array of SP, rearranged based TCT and proposed optimal interconnection topology are shown in Figure 26. In the uniform irradiance case-U, the global maximum peak power of SP, rearranged TCT and proposed optimal configurations or topology are the same i.e., $9620 \mathrm{~W}$ and the maximum power will be changed in different shading scenarios. The array global maximum power and mismatch or shading losses, fill-factor, efficiency of TCT array configurations under 14 different partial shading cases (Cases 1 to 14) are tabulated in Table 5.

Table 5. Array power, fill-Factor and efficiency of different configurations

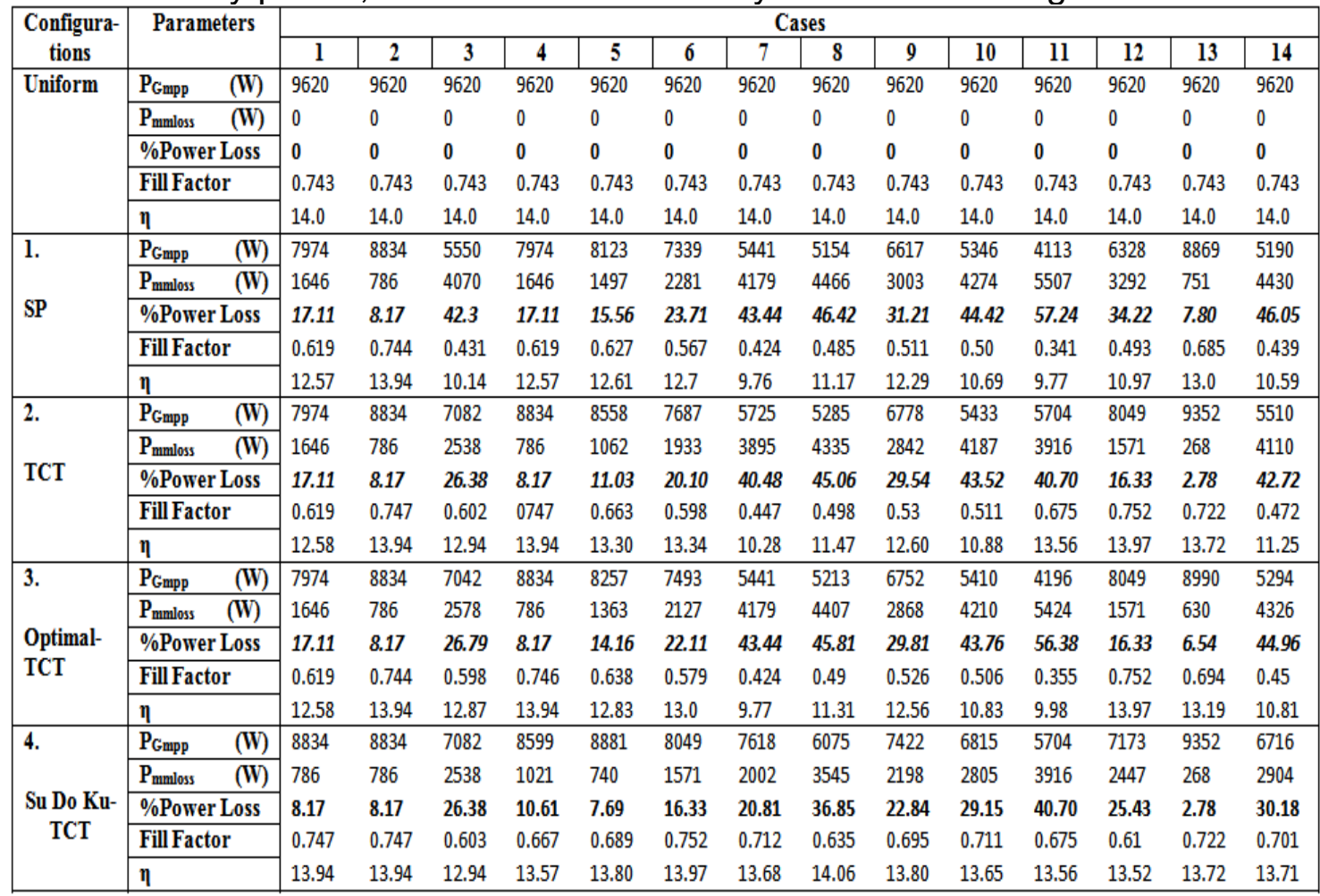




\begin{tabular}{|c|c|c|c|c|c|c|c|c|c|c|c|c|c|c|c|}
\hline \multirow{5}{*}{$\begin{array}{l}5 . \\
\text { Arrow } \\
\text { Su Do Ku- } \\
\text { TCT }\end{array}$} & $P_{\text {Gmpp }}$ & 8834 & 8834 & 6394 & 8013 & 8916 & 7702 & 7618 & 6480 & 7057 & 6752 & 5704 & 7058 & 9352 & 6716 \\
\hline & $\mathbf{P}_{\text {mmloss }} \quad(\mathrm{W})$ & 786 & 786 & 3226 & 1607 & 704 & 1918 & 2002 & 3140 & 2563 & 2868 & 3916 & 2562 & 268 & 2904 \\
\hline & \%Power Loss & 8.17 & 8.17 & 33.53 & 16.70 & 7.31 & 19.93 & 20.81 & 32.64 & 26.64 & 29.81 & 40.70 & 26.63 & 2.78 & 30.18 \\
\hline & Fill Factor & 0.745 & 0.745 & 0.544 & 0.521 & 0.691 & 0.654 & 0.712 & 0.762 & 0.66 & 0.635 & 0.675 & 0.549 & 0.722 & 0.70 \\
\hline & $\eta$ & 13.94 & 13.94 & 11.68 & 12.64 & 13.86 & 13.37 & 13.68 & 14.06 & 13.12 & 13.52 & 13.56 & 12.25 & 13.72 & 13.71 \\
\hline \multirow{5}{*}{$\begin{array}{l}6 . \\
\text { Ken Ken- } \\
\text { TCT }\end{array}$} & $P_{\text {Gmpp }}$ & 8704 & 8834 & 7082 & 8599 & 8916 & 7790 & 7617 & 6480 & 7057 & 6692 & 5704 & 7687 & 9352 & 6716 \\
\hline & $\mathbf{P}_{\text {mmloss }} \quad(\mathrm{W})$ & 916 & 786 & 2538 & 1021 & 704 & 1830 & 2003 & 3140 & 2563 & 2928 & 3916 & 1933 & 268 & 2904 \\
\hline & \%Power Loss & 9.52 & 8.17 & 26.38 & 10.61 & 7.31 & 19.02 & 20.82 & 32.64 & 26.64 & 30.43 & 40.70 & 20.1 & 2.78 & 30.18 \\
\hline & Fill Factor & 0.736 & 0.747 & 0.60 & 0.667 & 0.691 & 0.661 & 0.711 & 0.762 & 0.66 & 0.629 & 0.675 & 0.599 & 0.722 & 0.701 \\
\hline & $\eta$ & 13.73 & 13.94 & 12.94 & 13.57 & 13.86 & 13.52 & 13.68 & 14.06 & 13.12 & 13.40 & 13.56 & 13.34 & 13.72 & 13.71 \\
\hline \multirow{5}{*}{$\begin{array}{l}7 . \\
\text { Skyscrape } \\
\text { rs- TCT }\end{array}$} & $P_{\text {Gmpp }}$ & 8834 & 8834 & 7082 & 8030 & 8558 & 8049 & 7618 & 6075 & 7057 & 6752 & 5704 & 7167 & 9352 & 6262 \\
\hline & $\mathbf{P}_{\text {mmloss }} \quad(\mathrm{W})$ & 786 & 786 & 2538 & 1590 & 1062 & 1571 & 2002 & 3545 & 2563 & 2868 & 3916 & 2453 & 268 & 3358 \\
\hline & \%Power Loss & 8.17 & 8.17 & 26.38 & 16.52 & 11.03 & 16.33 & 20.81 & 36.85 & 26.64 & 29.81 & 40.70 & 25.49 & 2.78 & 34.90 \\
\hline & Fill Factor & 0.747 & 0.747 & 0.602 & 0.623 & 0.663 & 0.752 & 0.712 & 0.635 & 0.66 & 0.634 & 0.675 & 0.558 & 0.723 & 0.653 \\
\hline & $\eta$ & 13.94 & 13.94 & 12.94 & 12.67 & 13.30 & 13.97 & 13.68 & 13.18 & 13.12 & 13.52 & 13.56 & 12.44 & 13.72 & 12.79 \\
\hline \multirow{5}{*}{\begin{tabular}{l|}
8. \\
Non \\
Symmetric \\
\cline { 2 - 2 }
\end{tabular}} & $\mathbf{P}_{\text {Gmpp }}$ & 8834 & 8834 & 7097 & 8511 & 8916 & 7790 & 7618 & 6480 & 7057 & 6752 & 5704 & 7687 & 9352 & 6716 \\
\hline & $P_{\text {mmloss }} \quad(W)$ & 786 & 786 & 2523 & 1109 & 704 & 1830 & 2002 & 3140 & 2563 & 2868 & 3916 & 1933 & 268 & 2904 \\
\hline & \%Power Loss & 8.17 & 8.17 & 26.22 & 11.52 & 7.3 & 19.02 & 20.81 & 32.64 & 26.64 & 29.81 & 40.70 & 20.1 & 2.78 & 30.18 \\
\hline & Fill Factor & 0.747 & 0.747 & 0.664 & 0.659 & 0.691 & 0.662 & 0.711 & 0.762 & 0.66 & 0.634 & 0.675 & 0.598 & 0.723 & 0.70 \\
\hline & $\eta$ & 13.94 & 13.94 & 12.97 & 13.43 & 13.86 & 13.52 & 13.68 & 14.06 & 13.12 & 13.52 & 13.56 & 13.34 & 13.72 & 13.71 \\
\hline \multirow{5}{*}{$\begin{array}{l}9 . \\
\text { Chaotic } \\
\text { baker map } \\
\text { (CBM) - } \\
\text { TCT }\end{array}$} & $\mathbf{P}_{\text {Gmpp }}$ & 7899 & 8030 & 6442 & 8511 & 8650 & 8049 & 7499 & 6075 & 7041 & 6284 & 5704 & 7701 & 9352 & 6150 \\
\hline & $P_{\text {mmloss }} \quad(\mathrm{W})$ & 1721 & 1590 & 3178 & 1109 & 970 & 1571 & 2121 & 3545 & 2579 & 3336 & 3916 & 1919 & 268 & 3470 \\
\hline & \%Power Loss & 17.88 & 16.52 & 33.03 & 11.52 & 10.08 & 16.33 & 22.04 & 36.85 & 26.80 & 34.67 & 40.70 & 19.94 & 2.78 & 36.07 \\
\hline & Fill Factor & 0.613 & 0.623 & 0.549 & 0.66 & 0.67 & 0.752 & 0.638 & 0.636 & 0.60 & 0.59 & 0.675 & 0.654 & 0.723 & 0.578 \\
\hline & $\eta$ & 12.46 & 12.67 & 11.77 & 13.43 & 13.44 & 13.97 & 13.46 & 13.18 & 13.09 & 12.58 & 13.56 & 13.37 & 13.72 & 12.56 \\
\hline \multirow{5}{*}{$\begin{array}{l}10 . \\
\text { ODD } \\
\text { EVEN- } \\
\text { TCT }\end{array}$} & $P_{\text {Gmpp }}$ & 7899 & 8442 & 7082 & 8834 & 8558 & 6310 & 7486 & 6011 & 6967 & 6698 & 5704 & 8049 & 9352 & 5510 \\
\hline & $P_{\text {maloss }} \quad(\mathrm{W})$ & 1721 & 1178 & 2538 & 786 & 1062 & 3310 & 2134 & 3609 & 2653 & 2922 & 3916 & 1571 & 268 & 4110 \\
\hline & \%Power Loss & 17.88 & 12.24 & 26.38 & 8.17 & 11.03 & 34.40 & 22.18 & 37.51 & 27.57 & 30.37 & 40.70 & 16.33 & 2.78 & 42.27 \\
\hline & Fill Factor & 0.613 & 0.654 & 0.60 & 0.747 & 0.663 & 0.49 & 0.584 & 0.628 & 0.653 & 0.629 & 0.675 & 0.752 & 0.722 & 0.471 \\
\hline & $\eta$ & 12.46 & 13.32 & 12.94 & 13.94 & 13.30 & 10.95 & 13.44 & 13.04 & 12.96 & 13.41 & 13.56 & 13.97 & 13.72 & 11.25 \\
\hline \multirow{5}{*}{$\begin{array}{l}11 . \\
\text { Futoshiki- } \\
\text { TCT }\end{array}$} & $P_{\text {Gmpp }}$ & 8834 & 8834 & 6381 & 7974 & 8650 & 8049 & 7618 & 6075 & 7057 & 6752 & 5704 & 6925 & 9352 & 5510 \\
\hline & $\mathrm{P}_{\text {mmloss }} \quad(\mathrm{W})$ & 786 & 786 & 3239 & 1646 & 970 & 1571 & 2002 & 3545 & 2563 & 2868 & 3916 & 2695 & 268 & 4110 \\
\hline & \%Power Loss & 8.17 & 8.17 & 33.66 & 17.11 & 10.08 & 16.33 & 20.81 & 36.85 & 26.64 & 19.81 & 40.70 & 28.01 & 2.78 & 42.27 \\
\hline & Fill Factor & 0747 & 0.747 & 0.543 & 0.619 & 0.671 & 0.752 & 0.711 & 0.636 & 0.66 & 0.634 & 0.675 & 0.539 & 0723 & 0.471 \\
\hline & $\eta$ & 13.94 & 13.94 & 11.66 & 12.58 & 13.44 & 13.97 & 13.68 & 13.18 & 13.12 & 13.52 & 13.56 & 12.02 & 13.72 & 11.25 \\
\hline \multirow{5}{*}{$\begin{array}{l}12 . \\
\text { Latin } \\
\text { Square- } \\
\text { TCT }\end{array}$} & $\mathrm{P}_{\text {Gmpp }}$ & 8834 & 8834 & 6381 & 7974 & 8649 & 8049 & 7618 & 6075 & 7057 & 6752 & 5704 & 6925 & 9352 & 5510 \\
\hline & $P_{\text {numloss }} \quad(\mathrm{W})$ & 786 & 786 & 3239 & 1646 & 971 & 1571 & 2002 & 3545 & 2563 & 2868 & 3916 & 2695 & 268 & 4110 \\
\hline & \%Power Loss & 8.17 & 8.17 & 33.66 & 17.11 & 10.09 & 16.33 & 20.81 & 36.85 & 26.64 & 29.81 & 40.70 & 28.01 & 27.85 & 42.72 \\
\hline & Fill Factor & 0.747 & 0.747 & 0.543 & 0.619 & 0.669 & 0.752 & 0.712 & 0.635 & 0.66 & 0.635 & 0.675 & 0.541 & 0.722 & 0.472 \\
\hline & $\eta$ & 13.94 & 13.94 & 11.66 & 12.58 & 13.44 & 13.97 & 13.68 & 13.18 & 13.12 & 13.52 & 13.56 & 12.02 & 13.72 & 11.25 \\
\hline \multirow{5}{*}{$\begin{array}{l}13 . \\
\text { Magic } \\
\text { Square- } \\
\text { TCT }\end{array}$} & $P_{\text {Gmpp }}$ & 8834 & 7899 & 7460 & 8834 & 8650 & 7687 & 7618 & 6075 & 6778 & 5433 & 5704 & 8049 & 9352 & 6716 \\
\hline & $P_{\text {mmloss }} \quad(\mathrm{W})$ & 786 & 1721 & 2160 & 786 & 970 & 1933 & 2002 & 3545 & 2842 & 3887 & 3916 & 1571 & 268 & 2904 \\
\hline & \%Power Loss & 8.17 & 17.88 & 22.45 & 8.17 & 10.08 & 20.09 & 20.81 & 36.85 & 29.54 & 40.40 & 40.70 & 16.33 & 2.78 & 30.18 \\
\hline & Fill Factor & 0.747 & 0.612 & 0.635 & 0747 & 0.67 & 0.599 & 0.711 & 0.635 & 0.53 & 0.511 & 0.674 & 0.752 & 0.722 & 0.70 \\
\hline & $\eta$ & 13.94 & 12.46 & 13.63 & 13.94 & 13.44 & 13.34 & 13.68 & 13.18 & 12.60 & 10.88 & 13.56 & 13.97 & 13.72 & 13.71 \\
\hline \multirow{5}{*}{$\begin{array}{l}14 . \\
\text { Im based } \\
\text { TCT }\end{array}$} & $\mathrm{P}_{\text {Gmpp }}$ & 7899 & 8834 & 7097 & 8442 & 8916 & 7790 & 7499 & 6480 & 6778 & 5433 & 5704 & 8049 & 9352 & 6716 \\
\hline & $P_{\text {minloss }} \quad(\mathrm{W})$ & 1721 & 786 & 2523 & 1178 & 704 & 1830 & 2121 & 3140 & 2842 & 4187 & 3916 & 1571 & 268 & 2904 \\
\hline & \%Power Loss & 17.88 & 8.17 & 26.22 & 12.24 & 7.31 & 19.02 & 22.04 & 32.64 & 29.54 & 43.52 & 40.70 & 16.33 & 2.78 & 30.18 \\
\hline & Fill Factor & 0.612 & 0.747 & 0.55 & 0.654 & 0.691 & 0.662 & 0.638 & 0.762 & 0.53 & 0.511 & 0.675 & 0.752 & 0.722 & 0.70 \\
\hline & $\eta$ & 12.46 & 13.94 & 12.97 & 13.32 & 13.86 & 13.52 & 13.46 & 14.06 & 12.60 & 10.88 & 13.56 & 13.97 & 13.72 & 13.71 \\
\hline \multirow{5}{*}{$\begin{array}{l}15 . \\
\text { Vm based } \\
\text { TCT }\end{array}$} & $\mathrm{P}_{\text {Gmpp }}$ & 7974 & 8834 & 7082 & 8834 & 8558 & 7687 & 5725 & 5285 & 6778 & 5433 & 5704 & 8049 & 9352 & 5510 \\
\hline & $P_{\text {mmloss }} \quad(\mathrm{W})$ & 1646 & 786 & 2538 & 786 & 1062 & 1933 & 3895 & 4335 & 2842 & 4187 & 3916 & 1571 & 268 & 4110 \\
\hline & \%Power Loss & 17.11 & 8.17 & 26.38 & 8.17 & 11.03 & 20.1 & 40.48 & 45.06 & 29.54 & 43.52 & 40.70 & 16.33 & 2.78 & 42.72 \\
\hline & Fill Factor & 0.619 & 0.747 & 0.60 & 0.747 & 0.663 & 0.598 & 0.447 & 0.498 & 0.53 & 0.511 & 0.675 & 0.752 & 0.722 & 0.472 \\
\hline & $\eta$ & 12.58 & 13.94 & 12.94 & 13.94 & 13.30 & 13.34 & 10.28 & 11.47 & 12.60 & 10.88 & 13.56 & 13.97 & 13.72 & 11.25 \\
\hline
\end{tabular}

From the simulation results, it can be concluded that,

In partial shading case-1: Sudoku, Arrow Sudoku, skyscrapers, non-symmetrical, Futoshiki, LS and MS type of TCT array configurations have the maximum global peak power of $8834 \mathrm{~W}$.

$>$ In partial shading case-2: SP, TCT, proposed optimal TCT, Sudoku, Arrow Sudoku, Ken-Ken, skyscrapers, Non-symmetrical, futoshiki, LS, Im based and Vm based TCT configurations have the maximum power of $8834 \mathrm{~W}$. 
In partial shading case-3: Magic Square (MS) TCT array configuration has the maximum power of $7460 \mathrm{~W}$.

$>$ In partial shading case-4: TCT, proposed optimal TCT, Odd-Even, MS, Vm based TCT configurations have the maximum power of $8834 \mathrm{~W}$.

$>$ In partial shading case-5: Arrow Sudoku, Ken-Ken, Non-symmetric, Im based TCT configurations have the maximum power of $8916 \mathrm{~W}$.

$>$ In partial shading case-6: Sudoku, skyscraper, CBM, Futoshiki, LS type configurations have the maximum power of $8049 \mathrm{~W}$.

$>$ In partial shading case-7: Sudoku, Arrow Sudoku, skyscraper, Non-symmetric, Futoshiki, LS and MS type of SPV array configurations have the maximum power of $7618 \mathrm{~W}$.

$>$ In shading case-8: Arrow Sudoku, Ken-Ken, Non-symmetric, Im based TCT configurations have the maximum power of $6480 \mathrm{~W}$.

$>$ In partial shading case-9: Sudoku type TCT SPV array configuration has the maximum power of $7422 \mathrm{~W}$.

$>$ In partial shading case-10: Sudoku type TCT has the maximum power of $6815 \mathrm{~W}$.

$>$ In partial shading case-11: all rearrangement-based puzzle TCT configurations have the maximum global power of $5704 \mathrm{~W}$.

$>$ In partial shading case-12: TCT, optimal TCT, Odd-Even, MS, Im based and Vm based TCT configurations have the maximum power of $8049 \mathrm{~W}$.

$>$ In partial shading case-13: all rearrangement-based puzzle TCT configurations have the maximum global power of $9352 \mathrm{~W}$.

$>$ In partial shading case-14: Sudoku, Arrow Sudoku, Ken-Ken, Non-symmetric, MS, Im based TCT configurations have the maximum global power of $6716 \mathrm{~W}$.

$>$ Under partial shading conditions, rearrangement-based Total- Cross-Tied (TCT) array configurations show improved results compared to the conventional array topologies.

$>$ In the proposed method of optimal configuration, the requirement of ties or interconnections for electrical connections of modules in an array configuration are changed based on the shading pattern in the array.

$>$ Considering wiring losses in TCT and rearranged based TCT array topologies, the proposed optimal TCT array configuration has the better results compared to other rearranged based TCT array topologies. From the simulation results tabulated in Table 5, it can be concluded that the proposed optimal TCT array configuration, Sudoku, Arrow Sudoku, MS type of puzzle based TCT configurations have the highest global maximum peak power.

\subsection{Simulation Results:}

\section{Power-Voltage Characteristics of SPV TCT Array Configurations}

The performance characteristics (Power-Voltage) for different 6x6 size TCT SPV array configurations or topologies are shown in Figures 11 to 25. The global maximum peak powers of PV configurations under various shading cases are represented in Figure 26. The global maximum peak powers (GMPP) of each topology are tabulated in Table 5. 
a. Series(S)-Parallel (P) Configuration:

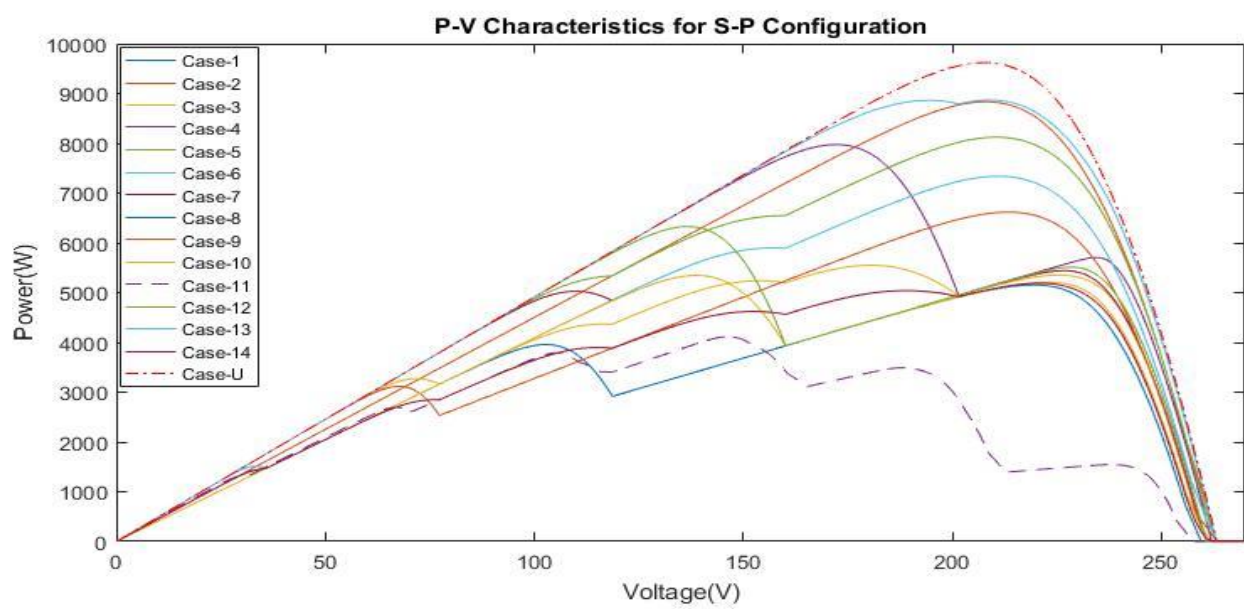

Figure 11. Output characteristics of $6 \times 6$ array S-P configuration

b. Total (T)-Cross(C)-Tied (T) configuration:

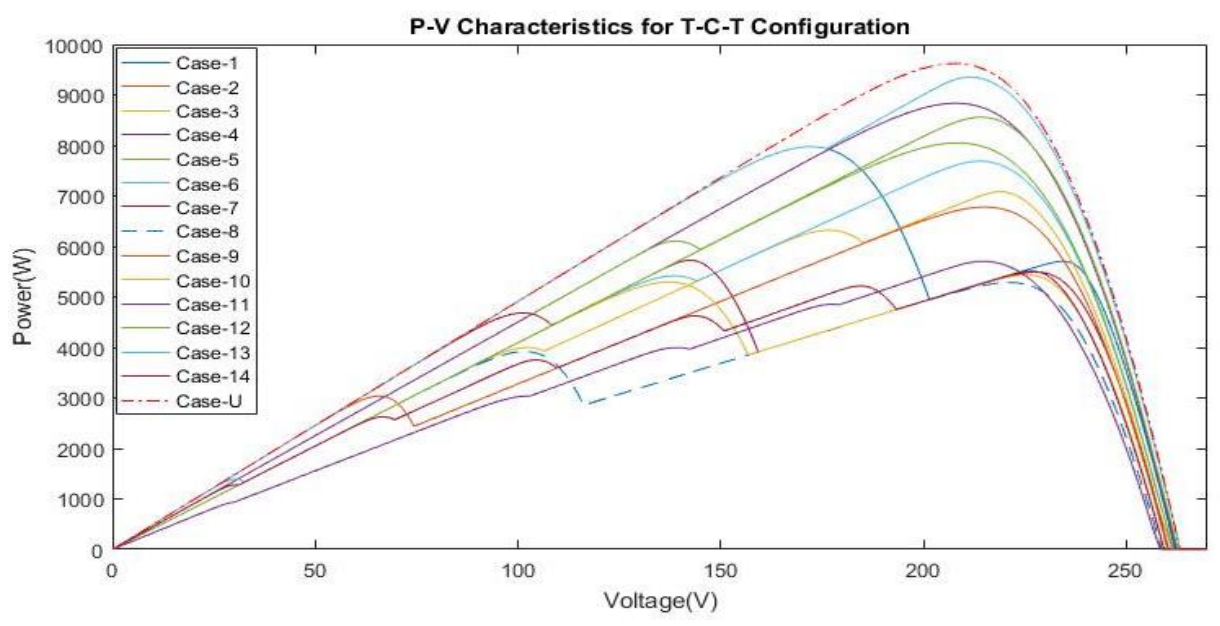

Figure 12. Output characteristics of $6 \times 6$ size TCT SPV array configuration

\section{c. Proposed optimal array configuration:}

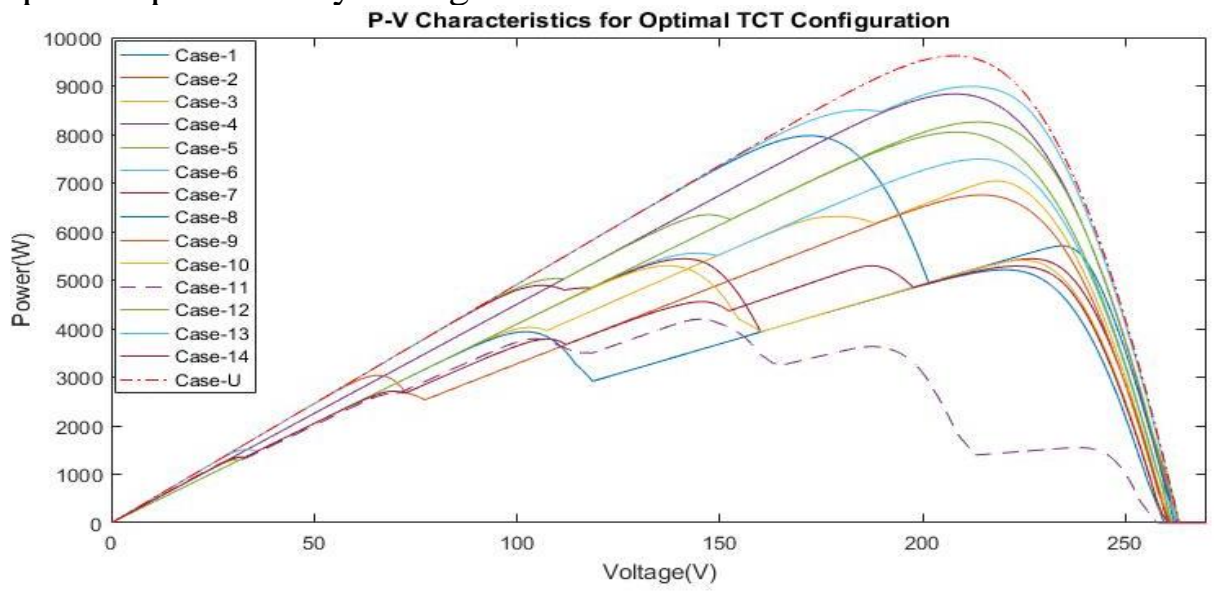

Figure 13. Output characteristics for proposed optimal configuration 
d. Su-Do-Ku based T-C-T configuration:

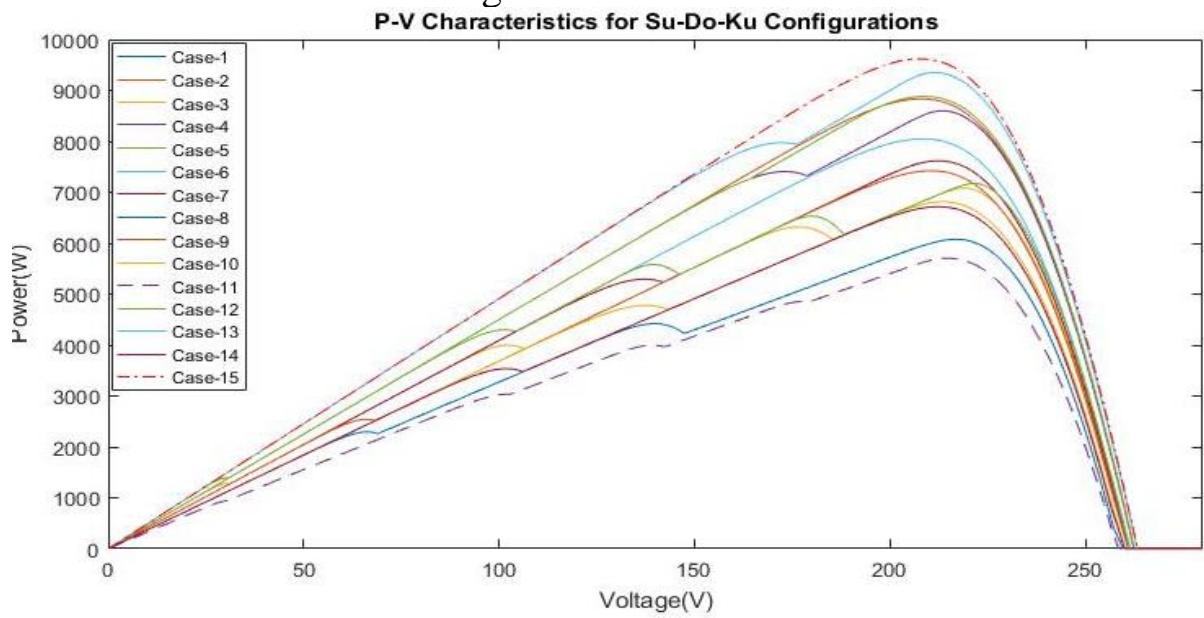

Figure 14. 6 × 6 array Sudoku-TCT configuration characteristics

e. Arrow Su-Do-Ku based TCT configuration:

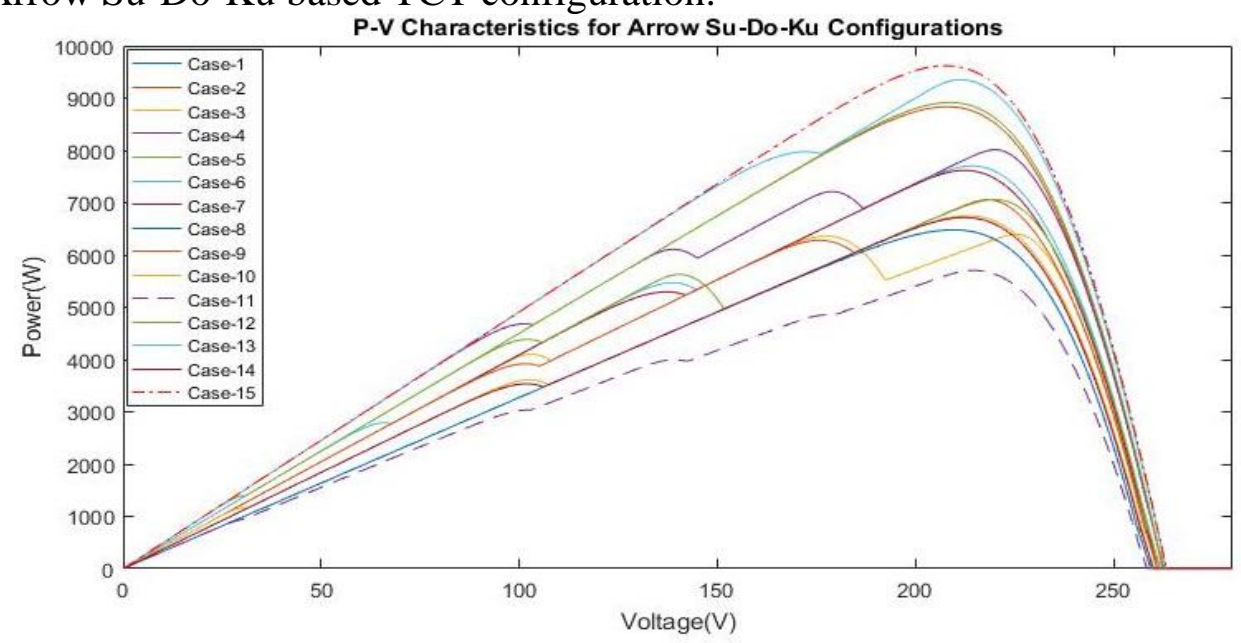

Figure 15. $6 \times 6$ array Arrow Sudoku TCT configuration characteristics

\section{f. Ken-Ken based TCT configuration:}

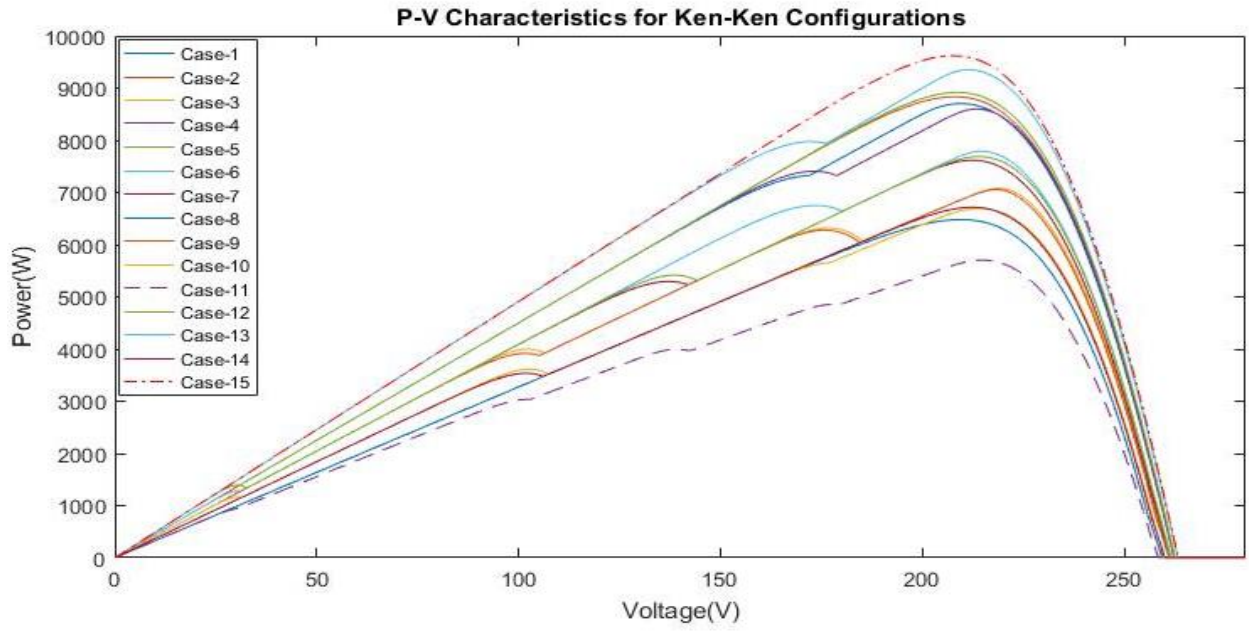

Figure 16. P-V characteristics for Modified Ken Ken-TCT configuration 
g. Skyscrapers-TCT configuration:

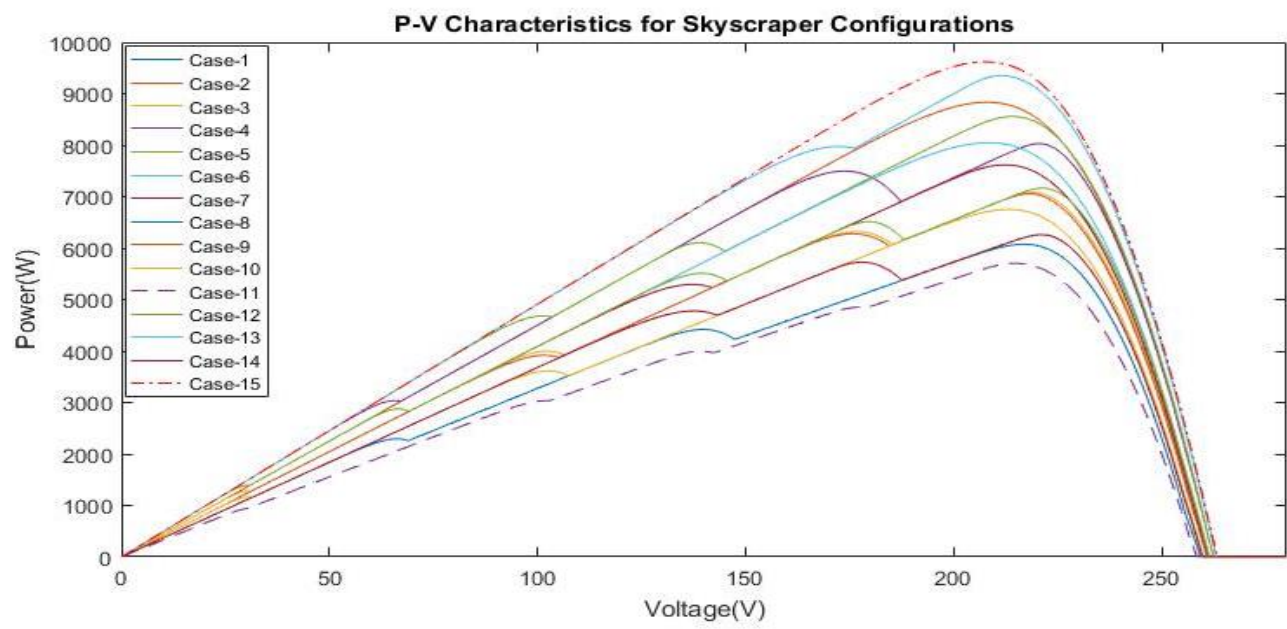

Figure 17. $\mathrm{P}-\mathrm{V}$ characteristics for Skyscrapers TCT configuration

h. Non-Symmetric TCT configuration:

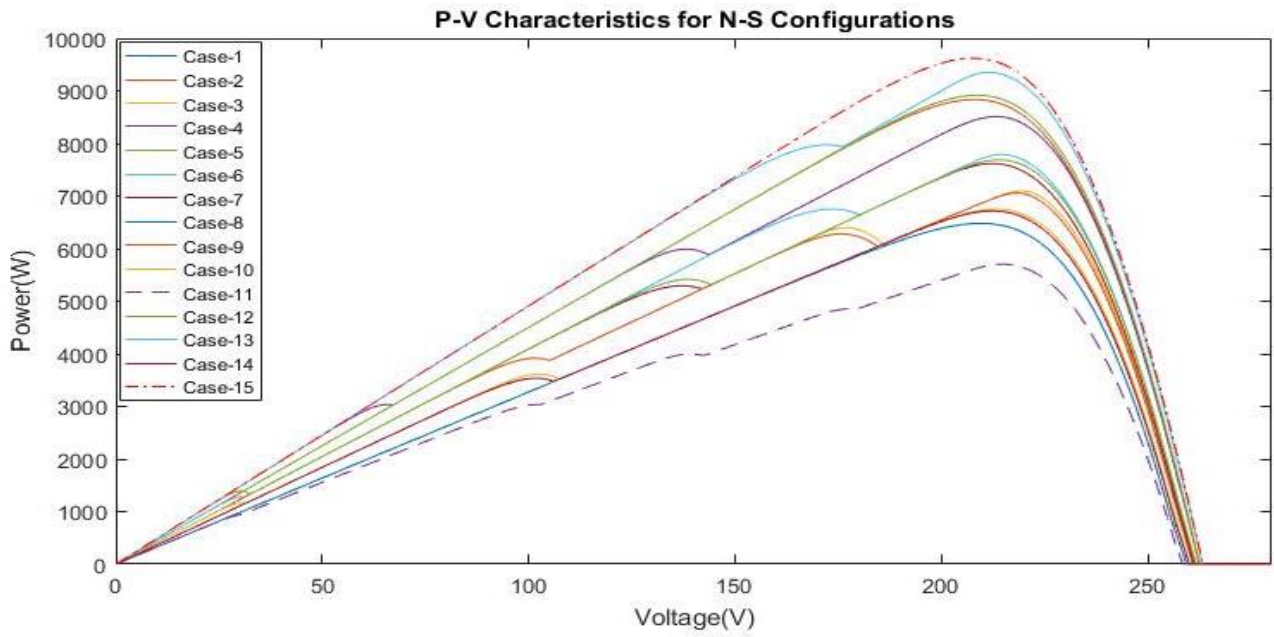

Figure 18. $\mathrm{P}-\mathrm{V}$ characteristics for Non- Symmetric TCT Re-configuration

\section{i. Chaotic Baker Map (CBM) TCT configuration:}

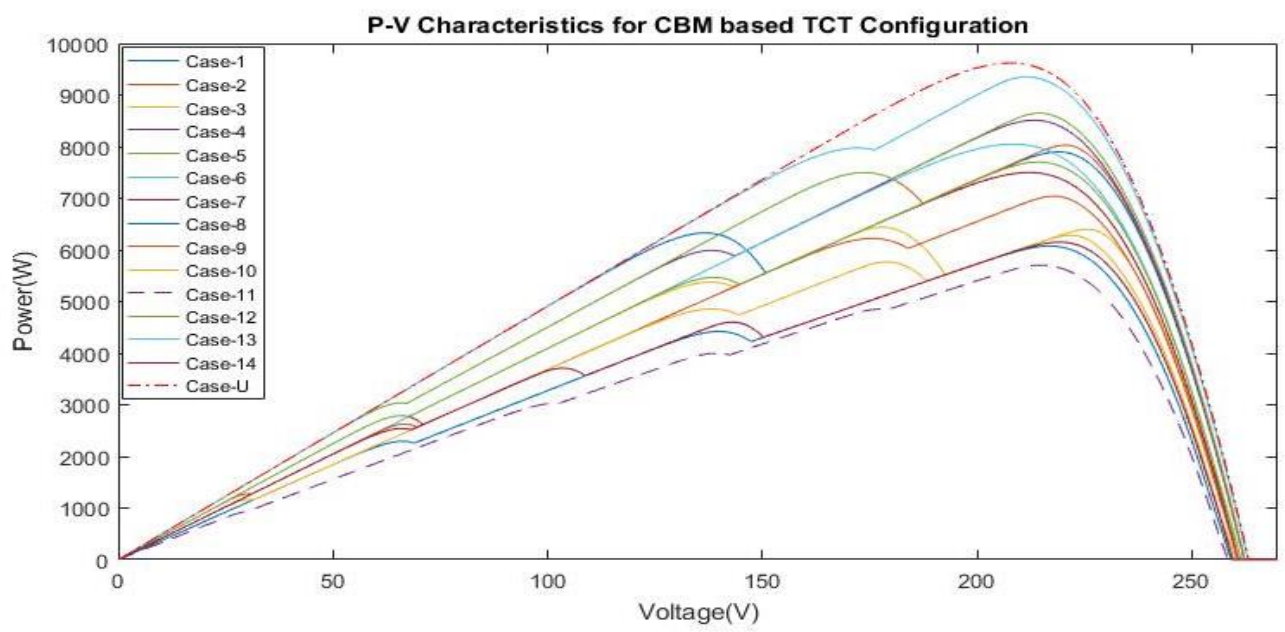

Figure 19. $\mathrm{P}-\mathrm{V}$ characteristics for CBM TCT Re-configuration 
j. ODD-EVEN based TCT configuration:

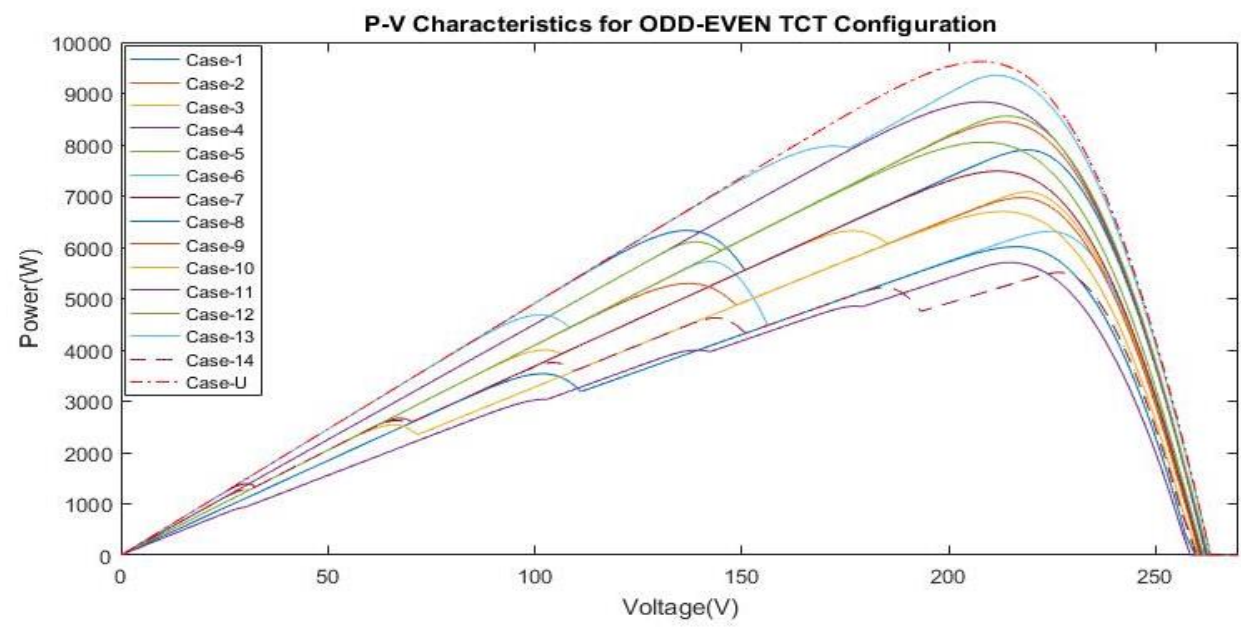

Figure 20. P-V characteristics for Odd Even TCT configuration

k. Futoshiki-TCT configuration:

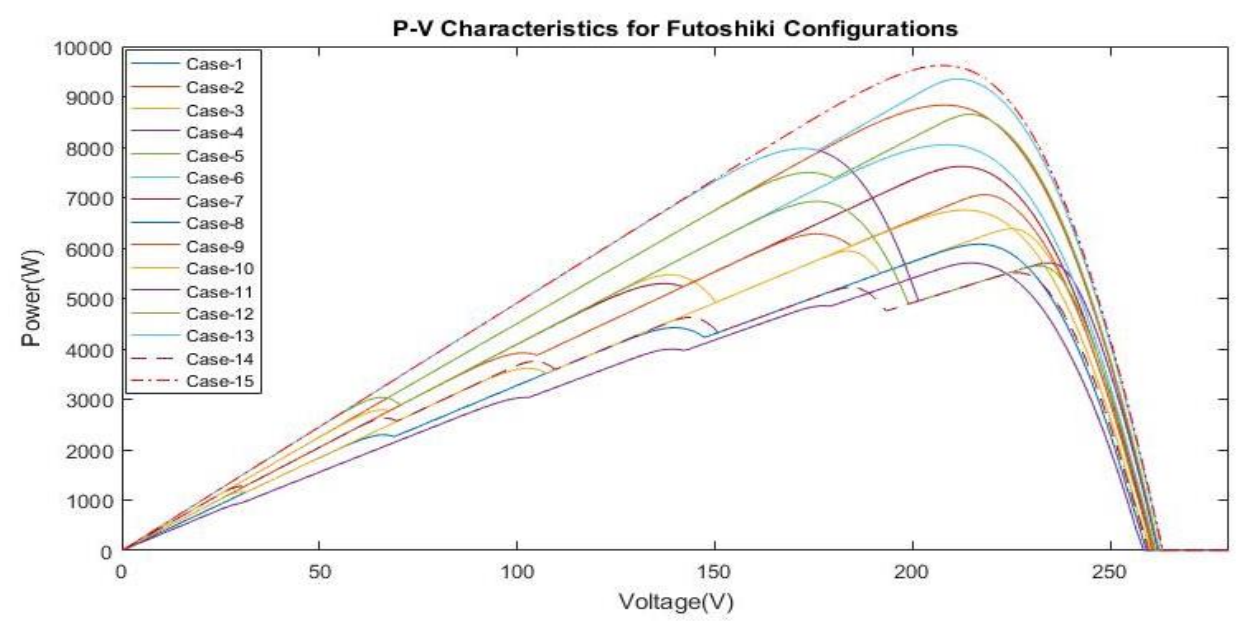

Figure 21. P-V characteristics for Futoshiki TCT configuration

1. Latin Square (LS) based TCT configuration:

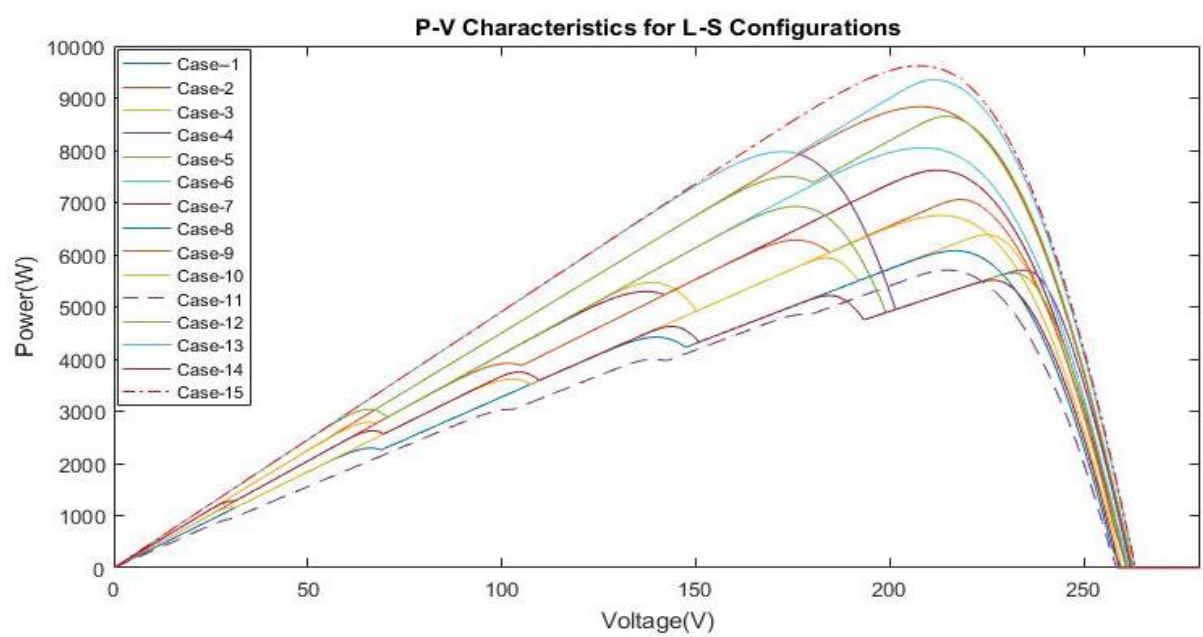

Figure 22. P-V characteristics for LS based TCT configuration 
m. Magic Square (MS) TCT topology:

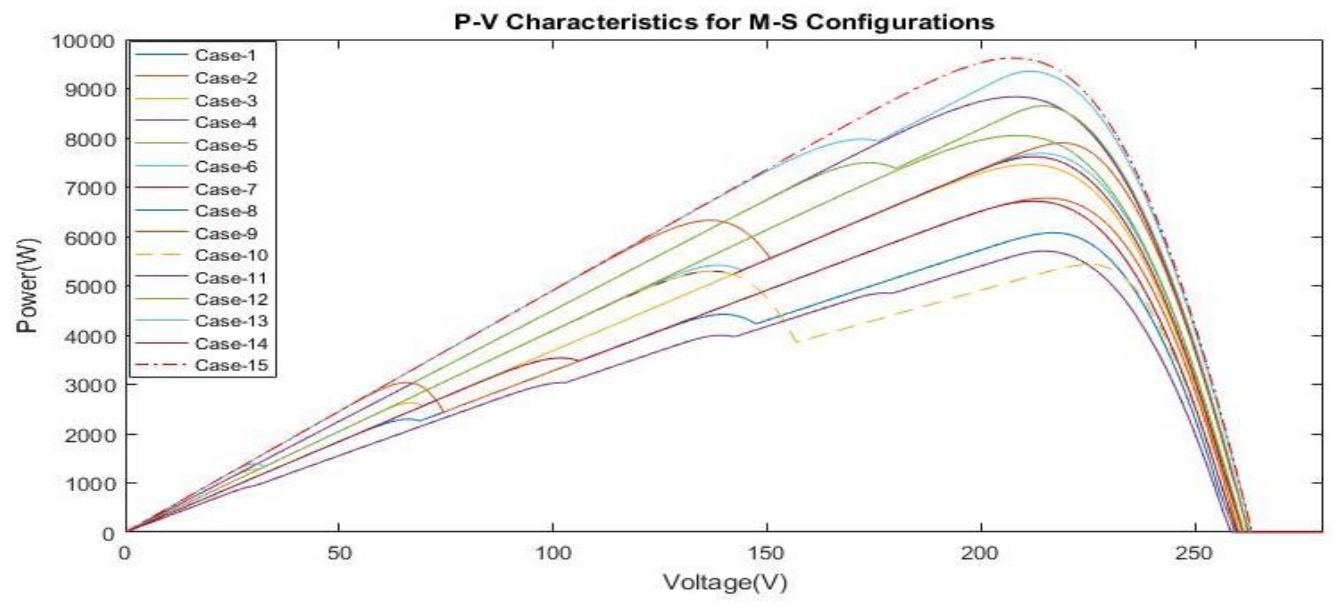

Figure 23. $\mathrm{P}-\mathrm{V}$ characteristics for MS TCT configuration

n. Im based TCT configuration:

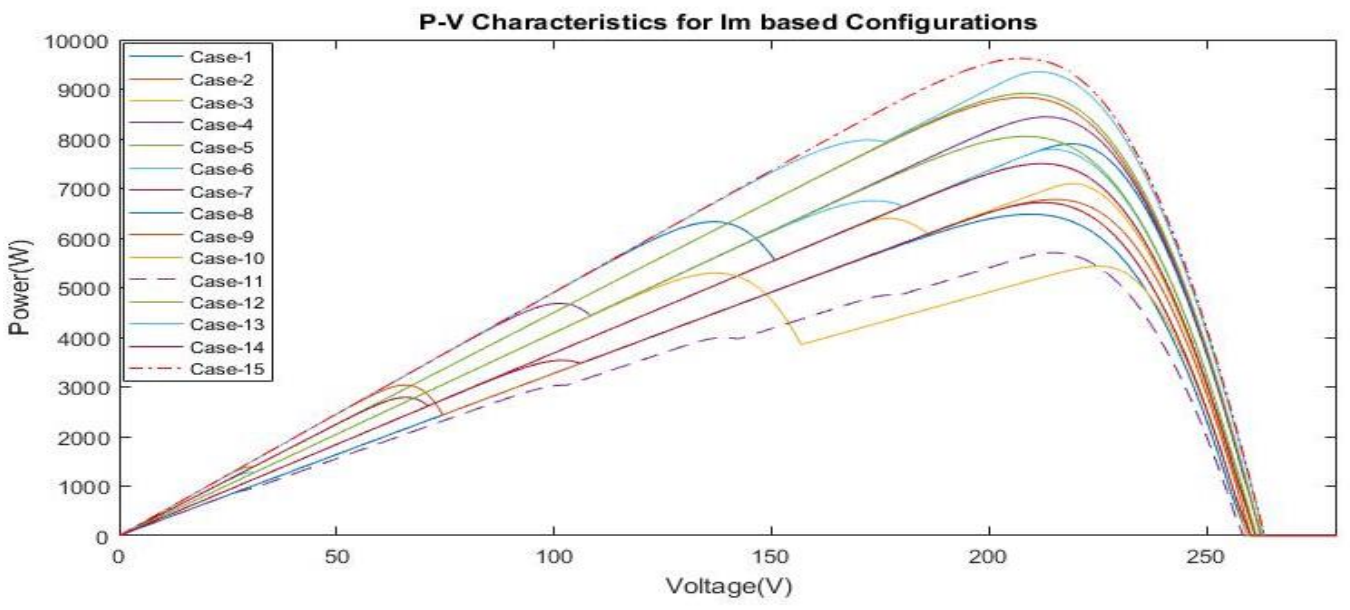

Figure 24. P-V characteristics for Im based TCT configuration

o. Vm based TCT configuration:

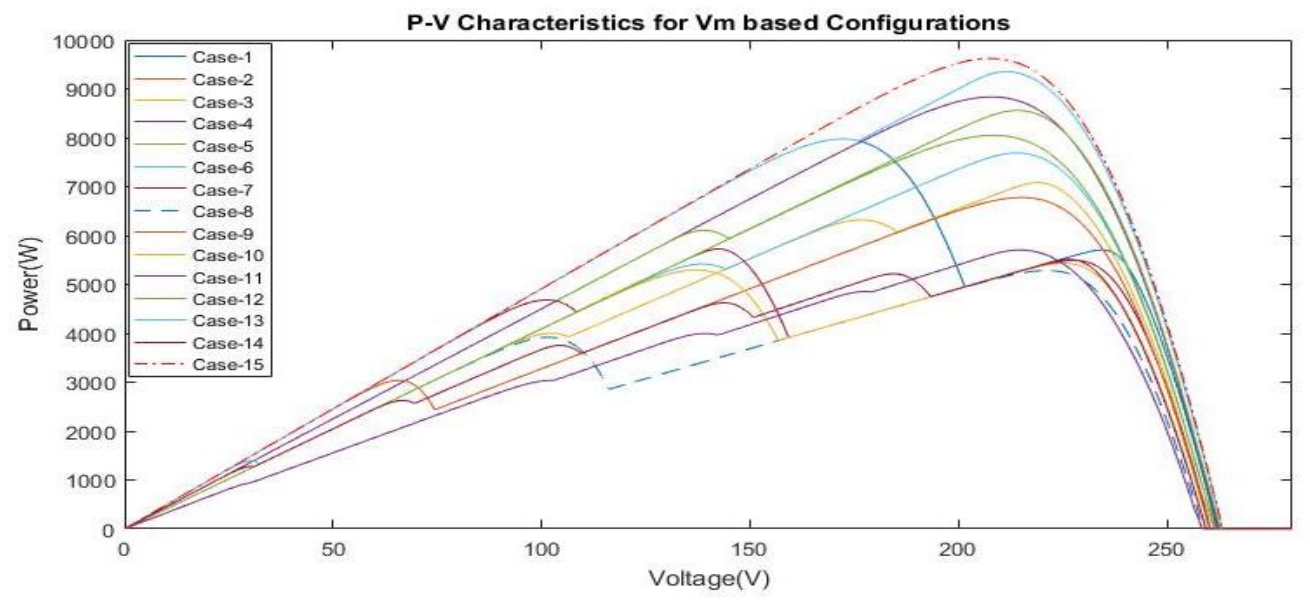

Figure 25. P-V characteristics for $\mathrm{Vm}$ based TCT configuration 


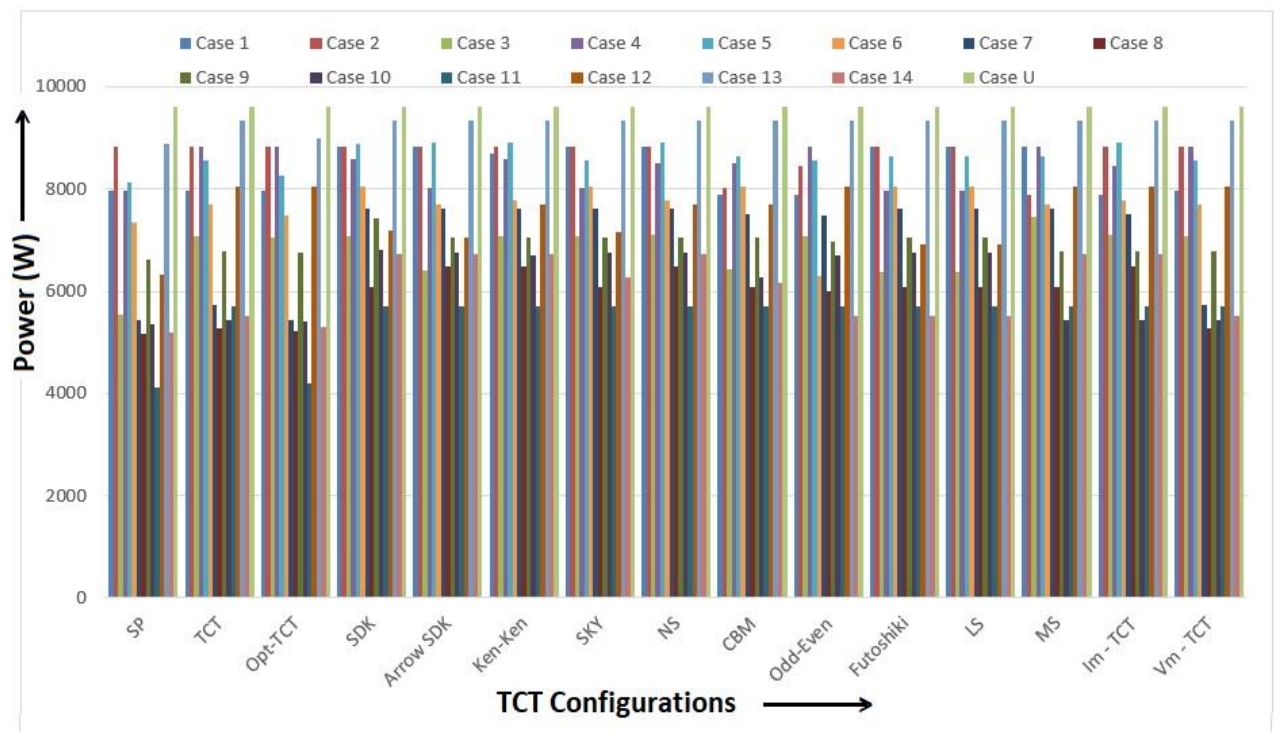

Figure 26. Global maximum powers of different TCT SPV array configurations

\section{CONCLUSIONS}

The proposed optimal array configuration method can be applied to an array of any size by simply dividing the PV system into a number of $2 \times 2$ sub arrays. The performance of rearranged array TCT configurations based on puzzle patterns including Sudoku, Arrow Sudoku, Ken-Ken, CBM, Odd-Even, Futoshiki, LS, MS, Im based and Vm based array TCT configurations are compared with the proposed optimal TCT configuration under fourteen different partial shading cases and one uniform un-shaded case-U. In the rearrangement method, the positioning of modules is changed, but electrical connections are unchanged. The wiring losses and requirement of wires for the rearrangement of modules are more due to repositioning of photovoltaic modules without altering electrical connections. Compared to rearranged based TCT array configurations, the proposed optimal method slightly reduces the mismatch losses, improves the array global maximum power and the fill factor, and minimizes the number of interconnections among modules, time required for wiring at the time of installation of PV system, installation cost of photovoltaic system and complexity of modules interconnection in an array. The rearranged based configurations have greater array power in all proposed partial shading conditions, but due to the extra wire length required for module interconnections in the array configuration, there is more wiring loss.

\section{CONFLICTS OF INTEREST}

The authors declare that there is no conflict of interests regarding the publication of this paper. 


\section{REFERENCES}

[1] J. Chattopadhyay, R. Singh, and O. Prakash, "Renewable Energy and its Innovative Technologies", Proceedings of ICEMIT 2017, Volume 1, Springer Singapore, 2019. DOI: 10.1007/978-981-13-2116-0

[2] M.I. Ahmad, M. Ismail, and S. Riffat, "Renewable Energy and Sustainable Technologies for Building and Environmental Applications: Options for a Greener Future", Springer International Publishing, 2016. DOI: 10.1007/978-3-319-31840-0 [3] J. Hossain and A. Mahmud, "Large Scale Renewable Power Generation: Advances in Technologies for Generation, Transmission and Storage", Springer Singapore, 2014. DOI: $10.1007 / 978-981-4585-30-9$

[4] D. Nguyen and B. Lehman, "Modeling and Simulation of Solar PV Arrays under Changing Illumination Conditions", in 2006 IEEE Workshops on Computers in Power Electronics, 2006, pp. 295-299. DOI: 10.1109/COMPEL.2006.305629

[5] H. Braun, S.T. Buddha, V. Krishnan, A. M. Banavar, and D. Srinivasan, "Topology reconfiguration for optimization of photovoltaic array output", Sustainable Energy, Grids and Networks, vol. 6, pp. 58-69, 2016. DOI: 10.1016/j.segan.2016.01.003

[6] G. Sai Krishna and T. Moger, "Reconfiguration strategies for reducing partial shading effects in photovoltaic arrays: State of the art", Solar Energy, vol. 182, pp. 429-452, 2019. DOI: 10.1016/j.solener.2019.02.057

[7] D. Nguyen and B. Lehman, "A reconfigurable solar photovoltaic array under shadow conditions", in 2008 Twenty-Third Annual IEEE Applied Power Electronics Conference and Exposition, 2008, pp. 980-986. DOI: 10.1109/APEC.2008.4522840

[8] G. S. Krishna and T. Moger, "Comparative Study on Solar Photovoltaic Array Configurations Under Irregular Irradiance Conditions", in 2018 8th IEEE India International Conference on Power Electronics (IICPE), 2018, pp. 1-6. DOI: 10.1109/IICPE.2018.8709512

[9] O. Bingöl and B. Özkaya, "Analysis and comparison of different PV array configurations under partial shading conditions", Solar Energy, vol. 160, pp. 336-343, 2018. DOI: 10.1016/j.solener.2017.12.004

[10] S. Pareek, N. Chaturvedi, and R. Dahiya, "Optimal interconnections to address partial shading losses in solar photovoltaic arrays", Solar Energy, vol. 155, pp. 537-551, 2017. DOI: 10.1016/j.solener.2017.06.060

[11] V.Bala Raju and Ch. Chengaiah, "Performance Analysis of Conventional, Hybrid and Optimal PV Array Configurations of Partially Shaded Modules", International Journal of Engineering and Advanced Technology (IJEAT), vol. 9, pp. 3061-3073, 2019. DOI: 10.35940/ijeat.A1661.109119

[12] Marcelo Gradella Villalva, Jonas Rafael Gazoli, and Ernesto Ruppert Filho, "Comprehensive approach to modeling and simulation of photovoltaic arrays", IEEE Transactions On Power Electronics, VOL. 24, NO. 5, May 2009, 1198-1208. DOI: 10.1109/TPEL.2009.2013862

[13] S. Pareek and R. Dahiya, "Power optimization of TCT configured PS-PV fields by forecasting the connection of modules", in 2015 Annual IEEE India Conference (INDICON), 2015, pp. 1-6. DOI: 10.1109/INDICON.2015.7443496

[14] H. S. Sahu and S. K. Nayak, "Power enhancement of partially shaded PV array by using a novel approach for shade dispersion", in 2014 IEEE Innovative Smart Grid Technologies - Asia (ISGT ASIA), 2014, pp. 498-503. DOI: 10.1109/ISGTAsia.2014.6873842 
[15] V.Bala Raju and Dr. Ch.Chengaiah "Modelling of solar PV array topologies under different partial shading conditions", in 2019 International Conference on Electrical, Communication, Electronics, Instrumentation and Computing (ECEIC), Kanchipuram • India, 2019.

[16] A. S. Yadav, R. K. Pachauri, Y. K. Chauhan, S. Choudhury, and R. Singh, "Performance enhancement of partially shaded PV array using novel shade dispersion effect on magic-square puzzle configuration”, Solar Energy, vol. 144, pp. 780-797, 2017. DOI: 10.1016/j.solener.2017.01.011

Article copyright: (C) 2020 V. Bala Raju, Dr. Ch. Chengaiah. This is an open access article distributed under the terms of the Creative Commons Attribution 4.0 International License, which permits unrestricted use and distribution provided the original author and source are credited. 